\title{
Las Imágenes de las Movilizaciones Climáticas Juveniles en la Prensa y la Televisión en España
}

\author{
María Gemma Teso Alonso ${ }^{1}$, Rogelio Fernández-Reyes ${ }^{2}$
}

\begin{abstract}
RESUMEN
Las movilizaciones climáticas de 2019 han supuesto una novedad en la acción climática. Una nueva generación de adolescentes y jóvenes han logrado llamar la atención de la sociedad sobre el reto del cambio climático, requiriendo a los gobernantes valentía para tomar medidas suficientes para cumplir con El Acuerdo de París, señalando a la ciencia como referente. Este hito histórico ha tenido a Greta Thunberg como rostro del movimiento estudiantil Fridays For Future junto a otras organizaciones. El objetivo general del presente artículo es estudiar la representación que ofrecen los medios de comunicación del activismo ambiental llevado a cabo por los jóvenes frente a la emergencia climática. La metodología empleada ha sido el análisis de contenido en televisión y en prensa a partir de un muestreo estructural. Entre los efectos de las movilizaciones juveniles, apoyadas por ciudadanía adulta, se pueden encontrar: un volumen inaudito de movimientos ciudadanos por el clima a nivel mundial, europeo y nacional; la identificación de la causa ambiental por parte de toda una generación; y haber logrado uno de sus objetivos: que se declarara institucionalmente la emergencia climática.
\end{abstract}

Palabras-clave: cambio climático, movilizaciones juveniles, Greta Thunberg, comunicación, imágenes.

\footnotetext{
1 Doctora por la Universidad Complutense de Madrid. Profesora en la Facultad de Ciencias de la Información (UCM). Grupo de Investigación MDCS (UCM). ORCID: http://orcid.org/0000-0001-9852-0255, email: gtesoalonso@gmail.com

2 Doctor por la Universidad de Sevilla, Miembro de los grupos de investigación GREHCCO (Universidad de Sevilla) y MDCS (Universidad Complutense de Madrid).ORCID: http://orcid.org/0000-0003-3955-3203, email: rogeliofreyes@hotmail.com
} 


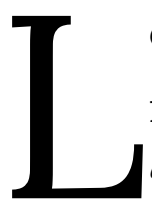

os rápidos cambios tecnológicos y culturales que han tenido lugar desde la revolución industrial han modificado nuestra sociedad transformándola en la "aldea global", que el filósofo Marshall McLuhan ${ }^{3}$ ya anticipó en la segunda mitad el siglo pasado. Este desarrollo industrial, tecnológico y social ha empleado grandes cantidades de energía que tradicionalmente han sido extraídas de los combustibles fósiles. Nuestra sociedad de la información es también la sociedad que más ha contribuido en los cambios de las condiciones ambientales de nuestro planeta, de tal forma que nos hemos adentrado en la nueva era geológica que algunos autores denominan Antropoceno ${ }^{4}$. Solo tres generaciones de humanos hemos consumido gran parte de los recursos naturales disponibles en el planeta, provocando un cambio climático antrópico que ya está mostrando sus efectos y que tendrán que padecer generaciones futuras. El derecho a la conservación del clima y de los ecosistemas esenciales para sostener la vida no es solo una cuestión de justicia intergeneracional, también es un problema de desigualdad. La vulnerabilidad ante los impactos del cambio climático (CC) está estrechamente relacionada con la pobreza (IPCC, 2014) y es especialmente grave entre los más jóvenes.

Los medios de comunicación tienen un importante rol como mediadores sociales en los procesos de mitigación y adaptación a las nuevas condiciones de vida. Los resultados de la investigación de la comunicación del cambio climático llevados a cabo hasta la fecha muestran etapas de mayor cobertura que se alternan con etapas de menor atención mediática ${ }^{5}$. Los principales hitos de la cobertura del cambio climático y del calentamiento global aparecen, principalmente, en los meses en los que se celebran las Cumbres de la Convención Marco de Naciones Unidas sobre el Cambio Climático. Otros elementos que han tenido especial repercusión han tenido que ver con los meses en los que se presentaron informes científicos del IPCC (Panel Intergubernamental de Cambio Climático), así como el Protocolo de Kioto, el documental An Inconvenient Trut de Al Gore, acuerdos, declaraciones y posicionamientos políticos o de regiones (Trump, Europa), acontecimientos

3 M. McLuhan \& B.R. Powers, The Global Village (Oxford University Press, 1989)

4 M. Arias Maldonado, Antropoceno. La política en la era humana (Barcelona: Taurus, 2018); P.J. Crutzen \& E.F. Stoermer, "The Anthropocene", Global Change Newsletter 41 (2000), 17-18; V. Rull del Castillo, El Antropoceno ( Madrid: Los libros de Catarata, 2018)

5 Boykoff, M. et al., World Newspaper Coverage of Climate Change or Global Warming, 2004-2020. Media and Climate Change Observatory Data Sets. Center for Science and Technology Policy Research, Cooperative Institute for Research in Environmental Sciences, University of Colorado (2000). 
internacionales, documentos como el informe Stern o la encíclica Laudato $\mathrm{Si}$, o eventos climáticos extremo ${ }^{6}$ A lo largo de 2019, las movilizaciones climáticas se hicieron sitio de manera inaudita en la cobertura mediática, contribuyendo a que fuera un año de récords de cobertura sobre la crisis climática. Por otro lado, el reconocimiento social del riesgo del cambio climático se ha visto entorpecido por el mensaje negacionista emitido por parte de algunos medios ${ }^{7}$ o por mandatarios como Donald Trump o Jair Bolsonaro. Tras el periodo récord en la atención mediática sobre el clima alcanzado a lo largo de 2019 se ha producido una bajada considerable a lo largo de 2020 por la crisis sanitaria del covid-198, que ha desplazado, al menos temporalmente, el protagonismo de las movilizaciones por el clima.

En el año 2018, la conceptualización del cambio climático como un gran riesgo inminente se recogió en el mensaje de alarma que lanzó la comunidad científica internacional, que robustecía el año 2030 como fecha de referencia para lograr el gran cambio que requiere poder atender los objetivos marcados en el Acuerdo de París. Se trataba del Informe "Global Warming $+1.5^{\circ} \mathrm{C}$ " emitido por el Panel de Expertos para el Cambio Climático de las Naciones Unidas (IPCC), presentado en octubre, que refrendaba informes anteriores y que posteriormente siguieron redundado otros informes científicos y meteorológicos. Este mensaje fue amplificado, primero, por Greta Thunberg y, posteriormente, por jóvenes de todo el mundo asociados al movimiento Fridays For Future, que se gestó alrededor de su reivindicación, así como otras agrupaciones.

La conciencia sobre la relevancia de la crisis climática en la ciudadanía internacional en 2019 creció gracias a las movilizaciones promovidas, principalmente, por jóvenes ${ }^{9}$. La figura de Greta fue decisiva. Estuvo nominada al Premio Nobel y fue designada como persona del año (2019) para la revista Times: "ha logrado convertir

6 R. Fernández-Reyes, J.L. Piñuel-Raigada y J.C. Águila-Coghlan, "Contraste de la cobertura periodística del cambio climático y del calentamiento global en España y en el ámbito internacional: IV-V Informes del IPCC y Bali-Copenhague-París", Revista Latina de Comunicación Social, 72 (2017), 1.165 a 1.185.

7 J. Boehnert, "Maping Climate Communitacion". Blog Ecolabs, (2014). Disponible en:

http://ecolabsblog.files.wordpress.com/2014/05/mapping-climate-communication-boehnert-may2014-v-1-flatlocked.pdf (28-05-2020); J. Painter, Climate Change in the Media: reporting risk and uncertainty Climate Change in the Media: Reporting Risk and Uncertainty (Oxford: RISJ, 2013)

8 M. Boykoff et al., World Newspaper Coverage of Climate Change or Global Warming, 2004-2020. Media and Climate Change Observatory Data Sets. Center for Science and Technology Policy Research, Cooperative Institute for Research in Environmental Sciences, University of Colorado (2020). doi.org/10.25810/4c3b-b819.

${ }^{9}$ Thackeray et al., "Civil disobedience movements such as School Strike for the Climate are raising public awareness of the climate change emergency", Global Change Biology 26(3), ( January 2020) 
una vaga preocupación sobre el planeta en un movimiento mundial que exige un cambio global". ${ }^{10}$ Inspiró a muchos otros adolescentes y jóvenes a organizar huelgas de estudiantes. Requirió a los gobernantes que prestaran atención a la ciencia y actuaran en consecuencia. Sin buscarlo, desencadenó la movilización de millones de ciudadanos y ciudadanas de todo el mundo. Algo inédito en las movilizaciones sociales. Greta Thunberg catalizó el rostro de dichas movilizaciones, llegando a cuadruplicar el número de referencias en la prensa con respecto a Fridays For Future $^{11}$. Ello a pesar que la joven sueca remitió continuamente a que el protagonismo se derivara también hacia otros jóvenes o agrupaciones.

Greta, quien se reconoce como asperger en su cuenta de Twitter, sufrió una depresión ante el dolor que le suponía conocer la realidad del cambio climático. Comenzó a no asistir a la escuela para situarse ante el Parlamento de su país con un cartón donde había escrito Skolstrejk för klimatet o "Huelga escolar por el clima", tras los incendios forestales y olas de calor de ese verano, en agosto de 2018. Se inspiró, en el marco de un mundo globalizado, en jóvenes de Florida que habían organizado, meses antes, March for our lives, pidiendo medidas ante las armas de fuego. Y se declaró en huelga todos los viernes hasta que Suecia cumpliera con el Acuerdo de París. El reconocimiento de su representatividad motivó que fuera invitada a participar en numerosos encuentros internacionales, tales como la COP 24 y la 25 y en los Foros de Davos de 2019 y 2020.

El éxito de su comunicación se puede deber al uso eficiente de recursos retóricos combinados con argumentos de propósito moral ${ }^{12}$, así como la coherencia de sus acciones, que alienta a la ciudadanía a seguirla ${ }^{13 .}$ Como veremos, los medios de comunicación abordan la figura de Greta de distintas maneras. Por ejemplo, en los meses previos a marzo de 2019, la adolescente sueca era tratada con un tono positivo o neutro en El País y en La Vanguardia. En El Mundo lo trata tanto con tono positivo,

\footnotetext{
${ }^{10}$ El País, 11 de diciembre de 2019

${ }^{11}$ R. Fernández-Reyes, "Greta cataliza la imagen del movimiento internacional" en EFEverde (15 de marzo de 2019). Disponible en https://www.efeverde.com/blog/creadoresdeopinion/greta-imagen-movimiento-internacional/

12 E.M. Vavilov, "Lessons about activism from a Swedish high school student: A rhetorical analysis of Greta Thunberg's public speeches on climate change" (Master Thesis, Jönköping University, 2019). Retrieved from http://urn.kb.se/resolve?urn=urn:nbn:se:hj:diva-46317

${ }^{13}$ S. Murray, "Framing a Climate Crisis : A descriptive framing analysis of how Greta Thunberg inspired the masses to take to the streets" (Dissertation, 2020). Retrieved from http://urn.kb.se/resolve?urn=urn:nbn:se:uu:diva-402643
} 
como neutro y negativo. Expansión ni siquiera la nombraba ${ }^{14}$. Lo que no cabe duda es del importante espacio mediático que adquirieron las movilizaciones por el clima en $2019^{15}$, así como en las redes sociales ${ }^{16}$. Por otro lado, en numerosas ocasiones, los medios de comunicación han reflejado ataques directos de grupos organizados de extrema derecha o ultra liberales a la joven sueca -a pesar de ser menor- o a las movilizaciones juveniles ${ }^{17}$.

La adaptación a las nuevas condiciones de vida del Antropoceno necesita del empoderamiento de los niños y jóvenes ${ }^{18 .}$ Asistimos a una incipiente transformación social en la que los jóvenes son protagonistas ${ }^{19}$, apoyados por miles de científicos de numerosos países. Una batalla por la transformación social que se libra en las calles y en los medios de comunicación y que, por el bien de todos los que habitamos el planeta, los jóvenes merecen ganar. Estos jóvenes, apoyados por otras muchas organizaciones sociales, no han dejado de reclamar cambios sociales estructurales en los modelos económicos y organizativos que prevalecen. Cambios que requieren la interacción comunicativa para reproducirse y consolidarse conforme a valores como la ética y la justicia social. Resulta, por lo tanto, especialmente relevante investigar la comunicación social de este fenómeno que tiene a los jóvenes como protagonistas, como elementos catalizadores que contribuyen a incrementar la urgencia en la adopción de medidas para mitigar el cambio climático y mejorar nuestra resiliencia ante sus impactos.

14 R. Fernández-Reyes, "Greta cataliza la imagen del movimiento internacional" en EFEverde (15 de marzo de 2019). Disponible en https://www.efeverde.com/blog/creadoresdeopinion/greta-imagen-movimiento-internacional/

15 R. Fernández-Reyes, "Crónica de la cobertura del cambio climático en prensa de 2019". Disponible en https://recambiacambioclimatico.files.wordpress.com/2020/01/16.-resumen-2019.pdf; Ted MacDonald "How broadcast TV networks covered climate change in 2019" (27 de febrero de 2020). Disponible en https://www.mediamatters.org/broadcast-networks/how-broadcast-tv-networkscovered-climate-change-2019; A. Nacu-Schmidt, J. Katzung y M. Boykoff, "A Review of Media Coverage of Climate Change and Global Warming in 2019", Media and Climate Change Observatory, Colorado University (2020), en https://scholar.colorado.edu/concern/articles/qn59q4937; Thackeray et al., "Civil disobedience movements such as School Strike for the Climate are raising public awareness of the climate change emergency", Global Change Biology 26(3) (January 2020)

16 J. Jung, P. Petkanic, D. Nan, J.H. Kim, "When a Girl Awakened the World: A User and Social Message Analysis of Greta Thunberg" Sustainability 12(7), ( 2020), 2707

17 Z. Bergmann \& R. Ossewaarde, "Youth climate activists meet environmental governance: ageist depictions of the FFF movement and Greta Thunberg in Germannewspaper coverage", Journal of Multicultural Discourses (2020); R. Lawson, "Resisting eco-misogyni in online spaces: using corpus linguistic to investigate reactions towards Greta Thunberg" (2019). Disponible en

http://www.academia.edu/RobertLawson

18 Back, Cameron \& Tanner, "Children and Disaster Risk Reduction: Taking stock and moving forward", (UNICEF, 2009); Mariangela La Manna, "Cambiamento climatico e diritti umani delle generazioni presenti e future: Greta Thunberg (e altri) dinanzi al Comitato sui diritti del fanciullo", in Diritti umani e diritto internazionale (1/2020), 217-223

19 J.M. Zafra, "Jeremy Rifkin: "Estamos ante la amenaza de una extinción y la gente ni siquiera lo sabe" (23 de abril de 2020), Climática. Disponible en https://www.climatica.lamarea.com/jeremy-rifkin-entrevista/; D. Robert, "Social tipping points are the only hope for the climate", en vox.com (29 de enero de 2020). Disponible en https://www.vox.com/energy-and-environment/2020/1/29/21083250/climate-change-social-tippingpoints 


\section{LAS IMÁGENES COMO REPRESENTACIÓN SOCIAL DE LA RESPUESTA CIUDADANA DE LOS JÓVENES ANTE EL CAMBIO CLIMÁTICO}

En contraste con las aproximaciones más tradicionales de la percepción del riesgo, la teoría de la representación social reconoce la importancia de los frames o encuadres de referencia sobre cómo un riesgo es conceptualizado por la población ${ }^{20}$. La teoría de la representación social constituye una aproximación socioconstructivista que atiende especialmente a la manera en la que la población conceptualiza el fenómeno del cambio climático como constructo social. La población emplea un repertorio de símbolos, metáforas e imágenes icónicas que circulan en su contexto socio-cultural para dar forma y comunicar un tema extraño que comporta además un riesgo. Las imágenes visuales, en particular, constituyen un elemento de representación importante 21.

Un importante rol de las imágenes es contribuir a representar de forma concreta un concepto abstracto. En este sentido, la información visual es especialmente relevante porque puede convertir en una imagen un tema o aspecto concreto del cambio climático. O’Neill and Nicholson-Cole ${ }^{22}$ identificaron dos dimensiones del imaginario de la población en relación con el cambio climático: imágenes externas comunicadas por los medios e imaginaciones visuales que las personas tienen en relación con este tema. Para Smith y Joffe la concreción de un concepto (objectification) y su fijación (anchoring) son esenciales para transformar un fenómeno extraño en algo cotidiano percibido por el sentido común de la población. En análisis de las imágenes visuales procedentes de los medios (prensa) y las asociaciones mentales de los entrevistados proporcionan fuertes evidencias de la resonancia de unas sobre las otras. El material visual que utilizan los medios es el que tiene mayor impacto en el público (public engagment), razón por la que se incluye el análisis de las imágenes en este estudio.

\footnotetext{
${ }^{20}$ R. Entman, "Framing: Toward Clarification of a Fractuired Paradigm". Journal of Communication 41 (1993), 51-58.

$21 \mathrm{~N}$. Smith and H. Joffe, "How the public engages with global warming: A social representations approach", Public Understanding of Science 22(1) (2012) 16-32

22 S.J. O'Neill and S. Nicholson-Cole, "Fear won't do it: Promoting positive engagement with climate change through visual and iconic representations". Sciene Communication 30(3) (2009), 355-379
} 
De acuerdo con Villafañe ${ }^{23,}$ resulta imposible establecer cualquier concepto monosémico de imagen, más allá de afirmar que toda imagen supone una modelización de la realidad o de definir las características de su naturaleza icónica. En este sentido, las imágenes pueden ser clasificadas de acuerdo con múltiples criterios. Para este estudio, se ha diferenciado entre la imagen secuencial empleada por la televisión como medio audiovisual y la imagen fija o aislada empleada por los fotógrafos de prensa. El concepto de imagen secuencial va más allá del concepto de imagen en movimiento, ya que alude no sólo a su dimensión temporal sino a la construcción de significado en base a la yuxtaposición de las imágenes.

Para Mitry ${ }^{24}$, el plano es la mínima unidad dentro del lenguaje audiovisual. El concepto de plano es también conflictivo y polisémico en función del contexto en el que se emplee. Mitry establece los parámetros que lo definen como Acción, Angulación y Campo, parámetros compatibles para el análisis de las imágenes fijas que emplea la prensa. Respecto a la imagen televisiva, en este texto se muestran las imágenes que corresponden a un solo frame o fotograma de un plano concreto, siendo la "acción" el contenido que representa, la "angulación" una característica que deriva de la angulación de la cámara (sólo respecto al eje vertical) y el campo la cantidad de espacio encuadrado, es decir, el tamaño del encuadre en relación con la figura humana (desde el plano general al primer plano). Estos parámetros han sido considerados como variables de análisis, a los que se ha añadido una clasificación de los distintos recursos visuales que pueden ser empleados por la prensa y la televisión, tales como gráficos o rótulos.

\section{OBJETIVOS Y ESTRATEGIA METODOLÓGICA DEL ESTUDIO}

La investigación llevada a cabo ha tenido como objetivo general estudiar la representación que ofrecen los medios de comunicación del activismo ambiental llevado a cabo por los jóvenes frente a la emergencia climática. Se analizan también los cambios que se han producido en la cobertura y el tratamiento mediático del 
cambio climático gracias al protagonismo de los jóvenes, atendiendo principalmente al mensaje que contienen las imágenes. Los objetivos específicos son:

- Identificar los marcos predominantes, el contenido y los titulares de la información sobre Greta y/o las movilizaciones de jóvenes.

- Explorar las actitudes de los protagonistas y las actitudes de los medios hacia ellos

- Analizar las imágenes de los jóvenes activistas como protagonistas de los distintos movimientos sociales por el clima.

- Averiguar qué mensajes prevalecen de Greta Thunberg y de otros jóvenes activistas.

De acuerdo con estos objetivos, el principal objeto de estudio lo constituyen las piezas correspondientes a la cobertura informativa de las movilizaciones juveniles por el clima en la prensa y en la televisión. Se trata de un estudio exploratorio sobre la cobertura mediática de las movilizaciones por el clima. Por ello, la técnica empleada ha sido el análisis de contenido de las piezas informativas de los diarios y de los registros de la información televisiva que tienen como referencia comunicativa el cambio climático y a los jóvenes como actores del relato, bien sea como protagonistas o declarantes, bien sea como aludidos por el periodista que elabora la información o por otros declarantes que ofrecen su testimonio.

Para llevar a cabo el análisis de contenido en televisión y en prensa se ha empleado una técnica de muestreo estructural ${ }^{25}$. El primer criterio de acotación para seleccionar las unidades de análisis en televisión consistió en la elección de los canales atendiendo a los siguientes criterios: mayor volumen de audiencia, cobertura nacional y programación generalista. Las cadenas elegidas fueron TVE-1, Tele 5, Antena 3 y La Sexta. Estos canales pertenecen a los tres grandes grupos mediáticos españoles (RTVE, Mediaset y Atresmedia), lo que garantiza la pluralidad de líneas editoriales. La fuente de datos ha sido la empresa Kantar Media. La búsqueda se ha realizado conforme palabras clave "cambio climático", "calentamiento global", "emergencia climática" o "crisis climática". El periodo de tiempo analizado ha sido la denominada "Semana de Acción Climática" celebrada del lunes 23 al domingo 29 de 
septiembre de 2019. La elección de esta semana garantiza el seguimiento de la cobertura informativa de tres fechas destacadas en la agenda mediática: el lunes 23, día de celebración de la Cumbre del Clima convocada por Naciones Unidas celebrada en N. York; el miércoles 25 de septiembre, día de presentación del Informe de la ONU sobre CC y Océanos y el viernes 27 de septiembre, día de celebración de la huelga mundial por el clima.

El volumen total de los registros televisivos en los que apareció el cambio climático como referencia comunicativa en las fechas señaladas ascendió a 90 unidades. De estas 90 unidades de análisis sólo en 69 registros el cambio climático es el tema principal y en 39 de ellos incluyen la participación de jóvenes activistas como actores en el relato.

En prensa se estudiaron todos los artículos en los que aparecían "Greta Thunberg", "movilizaciones por el clima" o "manifestaciones por el clima" en el día posterior a las principales jornadas de movilización que se desarrollaron en el año 2019: 16 de marzo, 25 de mayo, 21 y 28 de septiembre y 7 de diciembre. Los diarios estudiados son El País, El Mundo, La Vanguardia y Expansión, periódicos de amplia difusión que incluye a dos de ámbito nacional, uno predominantemente regional y otro específico del ámbito económico. Se trata de diarios que ya se estudian en MeCCO (Media Climate Change Observatory) ${ }^{26}$ y que permite contrastes con este estudio.

El protocolo de análisis aplicado incluye variables específicas para cada soporte (prensa y televisión) y variables comunes que han sido aplicadas de forma transversal. A continuación se detallan las variables empleadas y su categorización.

- Identificación de la unidad de análisis: fecha, soporte, medio.

- Contenido: titular, palabras clave y tema (impactos, causas, soluciones, protestas, otros).

- Tratamiento: Enmarcado, género periodístico (prensa) y género del programa (televisión) y contextualización espacial (global, europeo, 
nacional, local) y temporal de la información (presente, medio plazo y largo plazo).

- Los protagonistas de las movilizaciones por el clima:

- Greta Thunberg

- Fridays For Future

- Greta Thunber y organizaciones por el clima

- Organizaciones por el clima

- El contenido principal de declaraciones de los jóvenes activistas.

- La actitud de de los jóvenes activistas y de Greta: positiva (asertivo, empático, creativo), negativa (dudas, recelo, crítico, preocupación), neutra (aséptica) u otras.

- La actitud del medio hacia los jóvenes y hacia Greta: positiva (empatía, admiración, reconocimiento), negativa (crítica peyorativa, infravaloración) o neutra (aséptica).

- Las imágenes empleadas para la representación social de las movilizaciones en los medios ${ }^{27}$ :

- Tipología de recursos visuales (Fotografía/GráficoDatos/Tabla /Dibujo/Mapa-Infografía/NP-NC).

- $\mathrm{N}^{0}$ de imágenes en las que aparecen jóvenes en cada unidad de análisis

- Tamaño del encuadre

- Ángulo de la cámara (eje vertical)

\section{RESULTADOS}

Para el contraste de resultados entre televisión y prensa, de acuerdo con las variables trasversales empleadas para el análisis de ambos soportes, se emplearán sólo

\footnotetext{
${ }^{27}$ En el caso de la televisión, se ha analizado una sola imagen que muestra a jóvenes activistas por unidad de análisis. Atendiendo a la diversidad del contenido las imágenes, el/la analista ha seleccionado la más original y representativa de cada unidad.
} 
los resultados del análisis de los registros televisivos que tienen como actores del relato informativo a los jóvenes activistas. Como podemos apreciar en la tabla siguiente, se trata de 39 piezas del total de 90 obtenidas en las tres fechas señaladas. Se compararán los resultados porcentuales de cada soporte.

\section{LAS MOVILIZACIONES POR EL CLIMA EN LAS FECHAS Y MEDIOS ANALIZADOS}

En las tres fechas clave de la Semana de Acción Climática celebrada en septiembre de 2019, en los principales canales televisivos de España, se encontraron 39 registros que tienen como referencia de la comunicación a los activistas y a los jóvenes. Como puede comprobarse en la tabla siguiente, en todos ellos el cambio climático es tratado como el asunto o tema principal.

Tabla 1. La prioridad del CC como referencia informativa en televisión durante la cobertura de las tres fechas clave $(23,25$ y 27 de septiembre) de la Semana de Acción Climática

\begin{tabular}{|c|c|c|c|}
\hline \multirow{2}{*}{$\begin{array}{l}\text { REFERENCIA DE LA } \\
\text { COMUNICACIÓN }\end{array}$} & \multicolumn{2}{|c|}{ Prioridad del CC } & \multirow[t]{2}{*}{ Total } \\
\hline & $\begin{array}{c}\text { Es el asunto } \\
\text { principal }\end{array}$ & $\begin{array}{l}\text { Es un asunto } \\
\text { secundario }\end{array}$ & \\
\hline Activistas- Jóvenes & 39 & $\mathbf{0}$ & 39 \\
\hline Científicos- ciencia & 1 & 0 & 1 \\
\hline Comunicación- Información & 1 & 0 & 1 \\
\hline Cumbre Clima N. York- Políticos & 11 & 1 & 12 \\
\hline Acuerdo de París & 1 & 0 & 1 \\
\hline Desastres naturales & 5 & 0 & 5 \\
\hline Mar- Océanos- Biodiversidad & 7 & 1 & 8 \\
\hline Emergencia climática & 1 & 0 & 1 \\
\hline Otras medidas concretas & 2 & 0 & 2 \\
\hline Ley CC & 1 & 0 & 1 \\
\hline NP & 0 & 19 & 19 \\
\hline Total & 69 & 21 & 90 \\
\hline
\end{tabular}

Fuente: elaboración propia

Los siguientes gráficos muestran los resultados obtenidos en los distintos canales televisivos y fechas analizadas. Los resultados indican que la cobertura del 
cambio climático que tiene a los jóvenes y a los activistas como referencia se produce fundamentalmente en el canal televisivo La Sexta (grupo Atresmedia), seguida del canal de la televisión pública nacional TVE-1 (grupo RTVE) en segundo lugar y del canal Tele 5 (grupo Mediaset) en tercera posición.

Gráficos 1 y 2. Los activistas jóvenes como protagonistas del relato televisivo del cambio climático en los distintos canales y fechas analizadas.

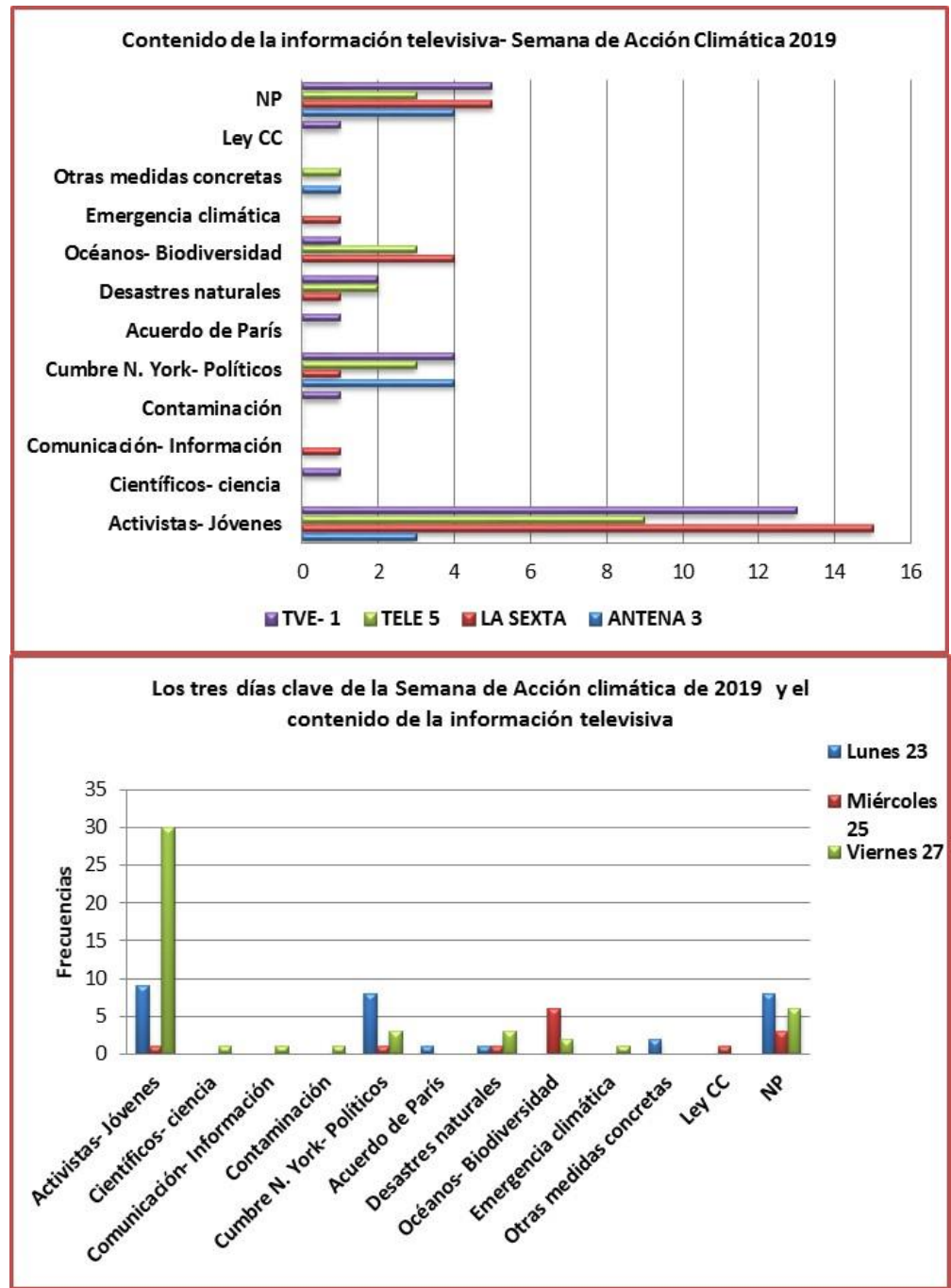

Fuente: elaboración propia

Como podemos apreciar en el gráfico 2, de los 90 registros analizados de la Semana de Acción Climática, las fechas de mayor protagonismo para los jóvenes activistas son, el día 27 de septiembre en primer lugar, fecha de celebración día de la huelga mundial por el clima; y el lunes día 23 en segundo lugar, día de celebración de la cumbre de la Acción Climática, que contó con la presencia de Greta Thunberg en la 
sede de Naciones Unidas y un gran número de activistas en las calles de la ciudad de Nueva York. Sin embargo, el miércoles día 25, fecha en la que se presentó el Informe del IPCC sobre el impacto del CC en los océanos, los jóvenes apenas aparecen en el contenido informativo. Este hecho, muestra la fuerte influencia de las agendas de otras esferas públicas en la cobertura mediática. En el caso de lunes, la cumbre como evento de la agenda política es objeto de la cobertura mediática que polariza su discurso entre protagonistas y antagonistas representados por los jóvenes activistas y el poder político. Las imágenes sobre la reacción de Greta Thunberg ante la inesperada aparición de Donald Trump en la cumbre, son un buen ejemplo de esta rivalidad entre los valores que representan la joven activista y el mandatario estadounidense.

\begin{abstract}
Imagen 1. Greta Thunberg se levanta ante la inesperada entrada de Donald Trump en la cumbre del clima (23/09/2019), dónde tan sólo estuvo diez minutos antes de asistir a otra cumbre sobre libertad religiosa que él mismo había convocado en la misma fecha en la sede de Naciones Unidas.
\end{abstract}

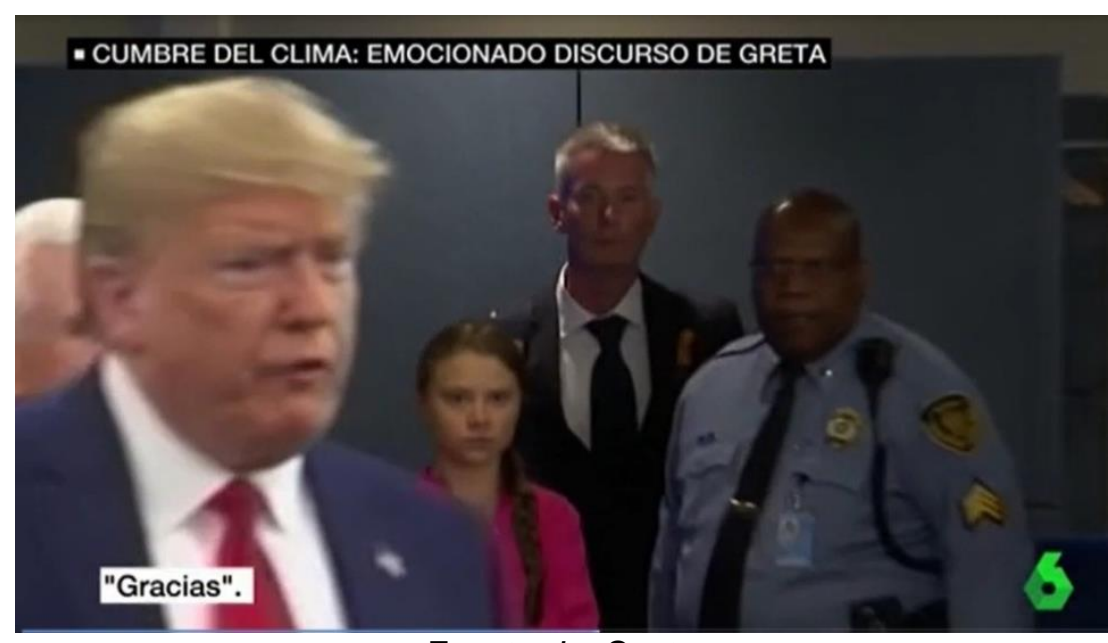

Fuente: La Sexta

Respecto a los resultados en la prensa (gráfico 3), cuando se estudian los artículos en los que aparecían "Greta Thunberg", "movilizaciones por el clima" o "manifestaciones por el clima" en el día posterior a las movilizaciones principales que se desarrollaron en el año 2019 nos encontramos con que el diario El País es el que más volumen de piezas informativas acumula (22), seguido de La Vanguardia (20), El Mundo (15) y el diario económico Expansión (2) que tan sólo ofrece información de las 
movilizaciones que tuvieron lugar el viernes anterior al inicio de la Cumbre del clima de Chile celebrada en Madrid en diciembre de 2019. Este orden en los diarios coinciden con el orden que muestran cuando se trata del abordaje de los términos "cambio climático" y "calentamiento global" en $\mathrm{MeCCO}$, salvo que Expansión suele estuvo, mayormente, en tercer lugar, y ahora está en el cuarto. Algo comprensible puesto se centra en el ámbito económico.

Gráfico 3. Unidades por diarios y por fechas analizadas

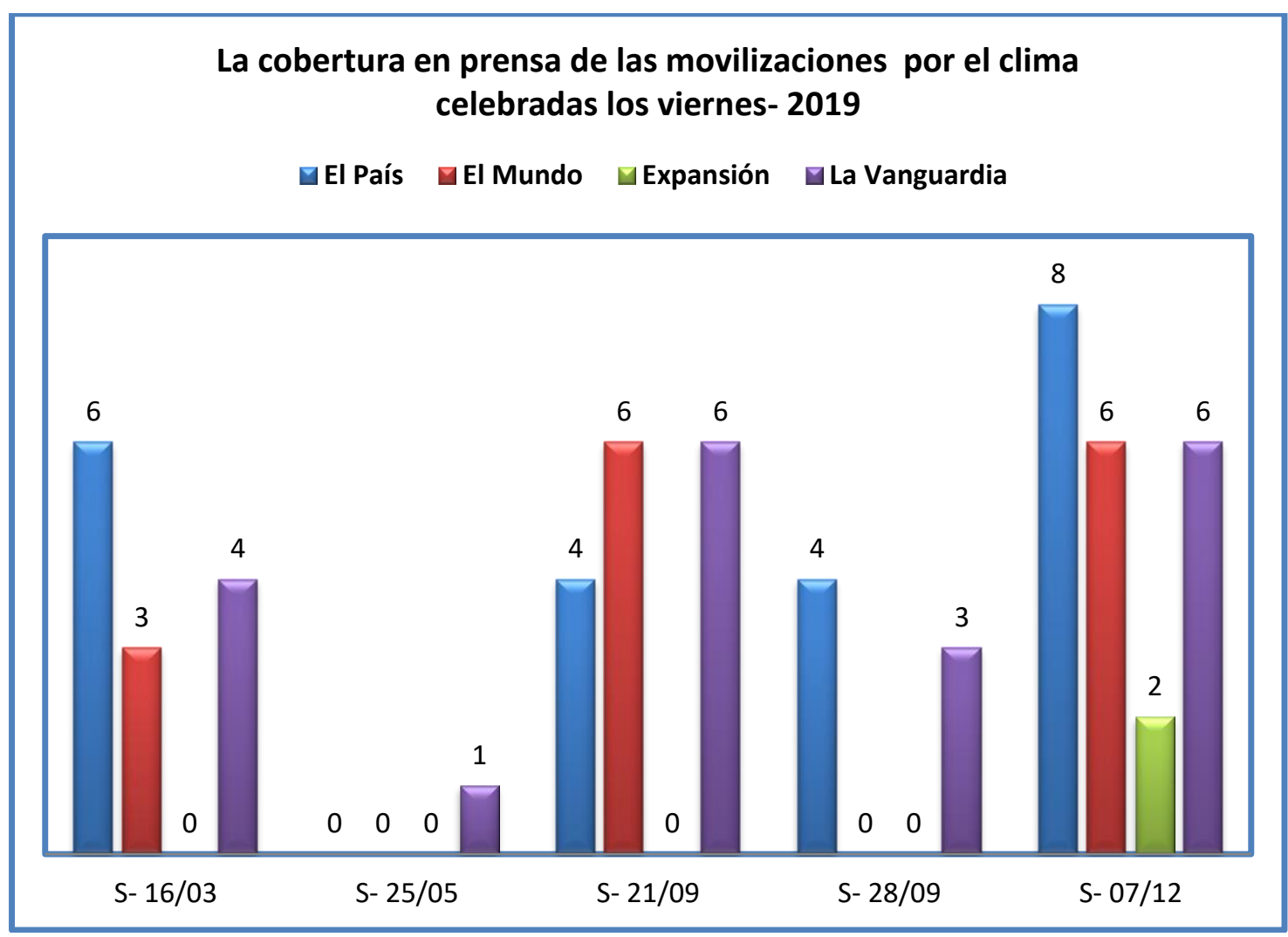

Fuente: elaboración propia.

\section{TRATAMIENTO DE LA INFORMACIÓN SOBRE EL ACTIVISMO AMBIENTAL EN LA PRENSA Y EN LA TELEVISIÓN: ENMARCADO, TEMAS Y GÉNERO PERIODÍSTICO}

En la prensa el enmarcado social se ha encontrado presente en la totalidad de los artículos analizados, lo cual es lógico atendiendo a los términos de búsqueda ("Greta Thunberg", "movilizaciones por el clima" o "manifestaciones por el clima"), 
mientras que los marcos de referencia político, económico y cultural tan sólo han estado presentes, de manera destacada, en un artículo cada uno.

En la televisión, cuyas palabras clave para la búsqueda eran "cambio climático", "calentamiento global", "emergencia climática" o "crisis climática", el enmarcado social también es el predominante en un 54\% de los casos. El segundo marco de referencia es el político en una $29 \%$ de los casos, seguido del enmarcado económico con un $9 \%$ de casos y del científico en un $5 \%$.

Los temas que han predominado en la prensa han sido la solución (55 de 59 artículos) y la protesta (53 de 59 artículos). En el caso de la televisión, las causas sólo son referidas en un $9 \%$ de los casos, los impactos en un $29 \%$ y las soluciones en un $62 \%$ de los casos, siendo también la opción mayoritaria.

Como podemos apreciar en el gráfico 4, los géneros periodísticos predominantes para la cobertura informativa de las movilizaciones sociales de los jóvenes por el clima en la prensa española son la noticia y el reportaje a partes iguales, ambos con un 33\% de los casos. La crónica supone el 18\% y la opinión el 11\%. 
Gráficos 4 y 5. Género periodístico (prensa) y género del programa (televisión) para la información sobre las movilizaciones por el clima. Porcentaje de casos.

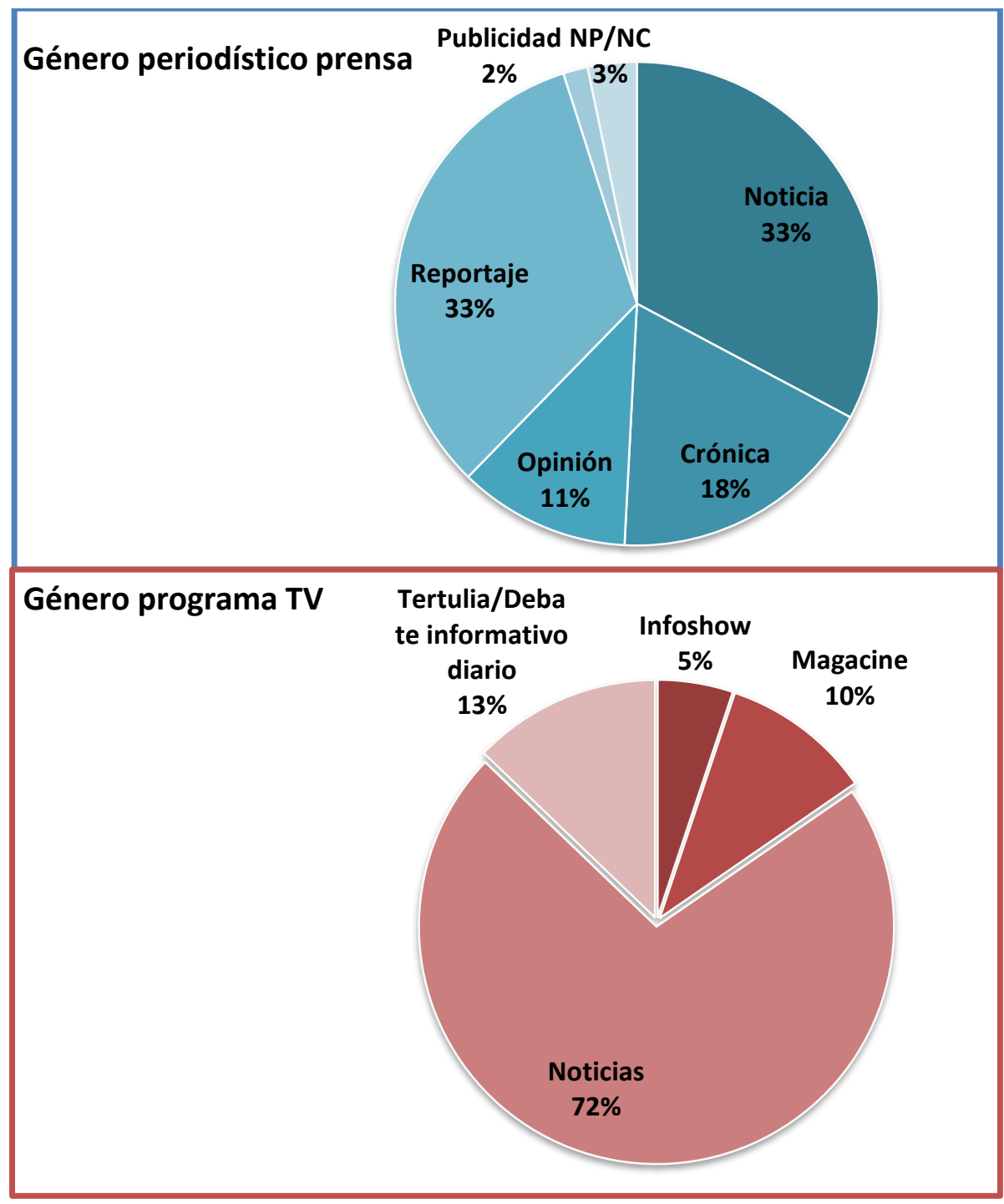

Fuente: elaboración propia

En la televisión (gráfico 5), encontramos que la mayor parte de la información relativa a las movilizaciones sociales por el clima, el 72\%, se encuentra presente en los informativos diarios. A continuación nos encontramos los programas informativos diarios centrados en el debate sobre la actualidad con un $13 \%$ de los casos y los programas magacines. En ambos casos, la información aparece en secciones de opinión de estos programas, ya que los magacines matinales de las principales cadenas incluyen también una mesa de debate sobre la actualidad. Incluso en el programa infoshow "Aruser@s" se incluye opinión en clave de humor. En las fechas analizadas para cada soporte, se aprecia menor peso de la opinión y mayor diversidad 
en cuanto al tratamiento informativo en los diarios analizados que en los canales de televisión.

Imagen 2: Debate dentro del programa magazine matinal de Ana Rosa Quintana

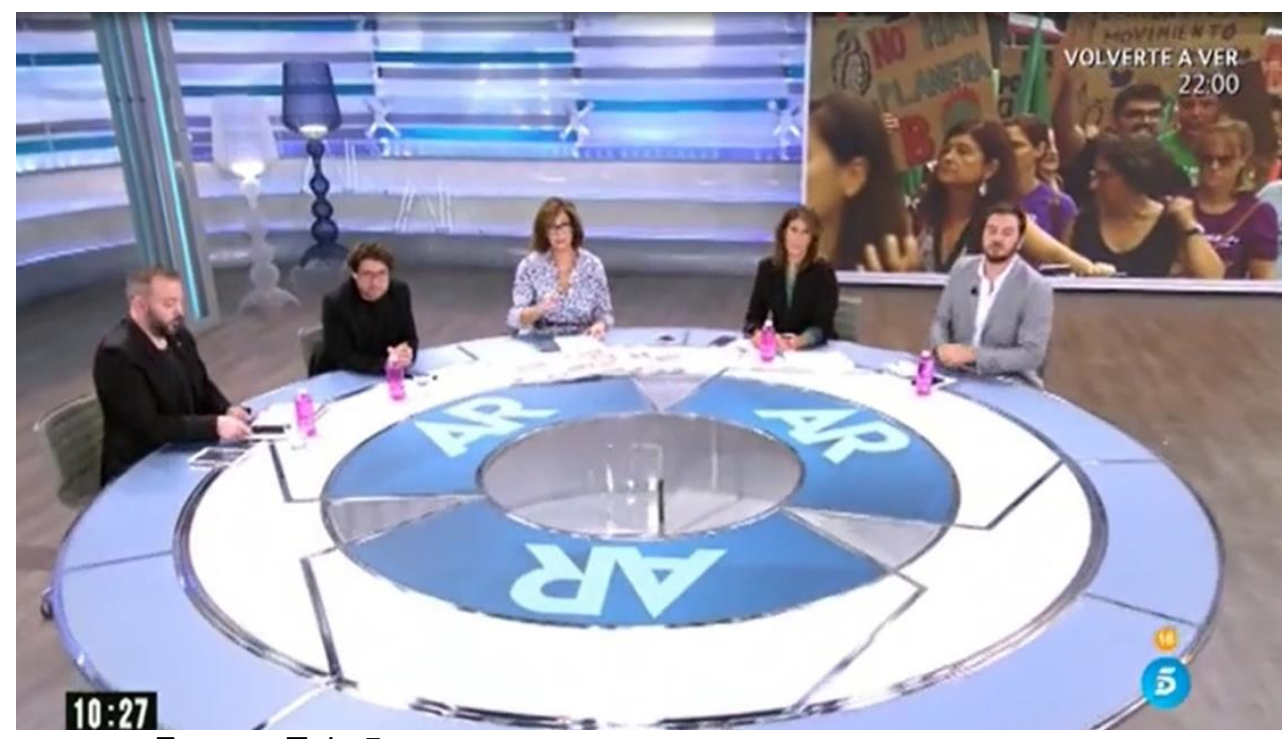

Fuente: Tele 5

\section{CONTEXTO ESPACIAL Y TEMPORAL}

Cuando se analiza el contexto espacial de las piezas analizadas se observa que prevalece una contextualización mundial en ambos soportes, con mayor proporción en el caso de la prensa. En la televisión, el ámbito estatal también es el marco para buena parte de las piezas. 
Gráfico 6. Unidades por contexto espacial

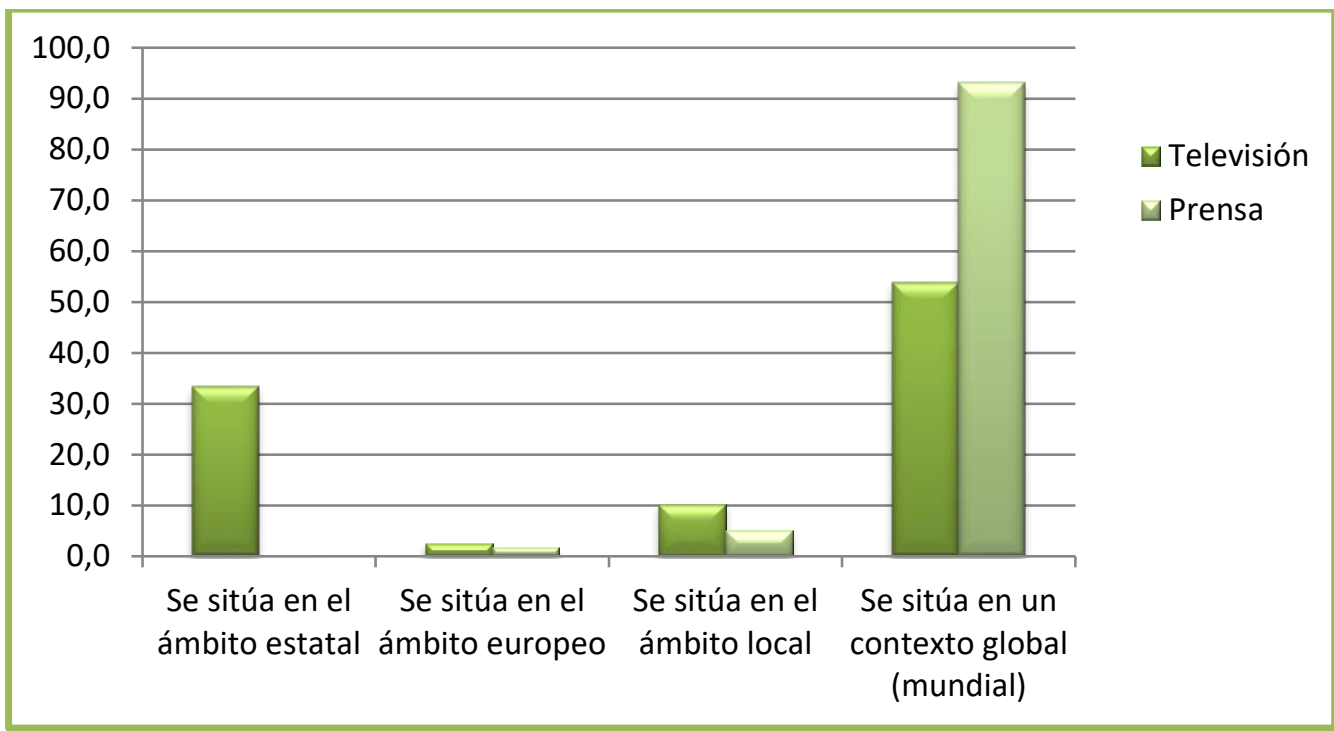

Fuente: elaboración propia

En el 100 \% de las publicaciones de prensa analizadas se sitúan en el contexto temporal que denominamos presente o futuro inmediato. La totalidad del contenido de las piezas se centra en un requerimiento de actuación inmediato. En televisión, la mayor parte de los registros también se sitúan ante la emergencia climática haciendo referencia a un contexto temporal inmediato en el 87,2\% de los casos. Encontramos también que en el 38\% de los registros televisivos se alude al fenómeno del cambio climático en dos contextos temporales en la misma pieza, señalando la urgencia en el presente y los impactos y medidas que hay que poner en marcha de inmediato y en el medio plazo (siguientes dos décadas). Tan solo un registro se sitúa en el escenario del largo plazo.

\section{LOS ACTIVISTAS COMO PROTAGONISTAS DEL CONFLICTO CLIMÁTICO}

En la prensa, los activistas son protagonistas en la totalidad de los artículos debido a los términos de búsqueda utilizados para el análisis. Los políticos son protagonistas en tres artículos, la ciudadanía en dos y los negacionistas en uno. En el caso de la televisión, si bien en todas las noticias de la muestra analizadas aparecen 
imágenes de los jóvenes activistas, éstos son los principales protagonistas en el $38 \%$ de los casos. Comparten este protagonismo en pantalla con los periodistas profesionales que intervienen como mediadores desde el lugar de los hechos en un $36,2 \%$ de los registros, cubriendo manifestaciones, desde la sede de las Naciones Unidas o como invitados a la mesa de debate en un programa de actualidad. Los políticos acaparan el protagonismo en el $20,3 \%$ de los casos y los ciudadanos anónimos que no se asocian con ninguna organización social son los protagonistas en el 4,34\% de los casos televisivos.

Cuando los protagonistas de la información son los activistas, destaca el protagonismo de Greta Thunberg al frente de las movilizaciones sociales por el clima, especialmente del movimiento Fridays For Future. En el gráfico 7 se ofrece la comparación entre prensa y televisión a la hora de distribuir el protagonismo en sus informaciones, bien sea para Greta en solitario o junto a otras organizaciones, bien sea dedicado al movimiento Fridays For Future en solitario o a un conjunto del que participan otras organizaciones. Comprobamos que Greta acapara un protagonismo mayor en la prensa que en la televisión, quizás porque en los diarios se usan menos imágenes y éstas se enfocan hacia la joven sueca como el rostro de las movilizaciones. El protagonismo más frecuente en prensa lo muestra la combinación Greta Thunberg y las movilizaciones $\mathrm{u}$ organizaciones por el clima, que aparecen en un $50 \%$ de los artículos. Es muy raro que aparezca Fridays For Future y no aparezca Greta. Y tan solo en un $15 \%$ aparece Greta sin referencia a agrupaciones. En la televisión, las organizaciones sociales por el clima y el movimiento Fridays For Future gozan de mayor cobertura, si bien Greta es también un importante referente en los canales televisivos. 
Gráfico 7. Los protagonistas de la información sobre las movilizaciones juveniles por el clima en la prensa y en la televisión. Porcentaje de casos.

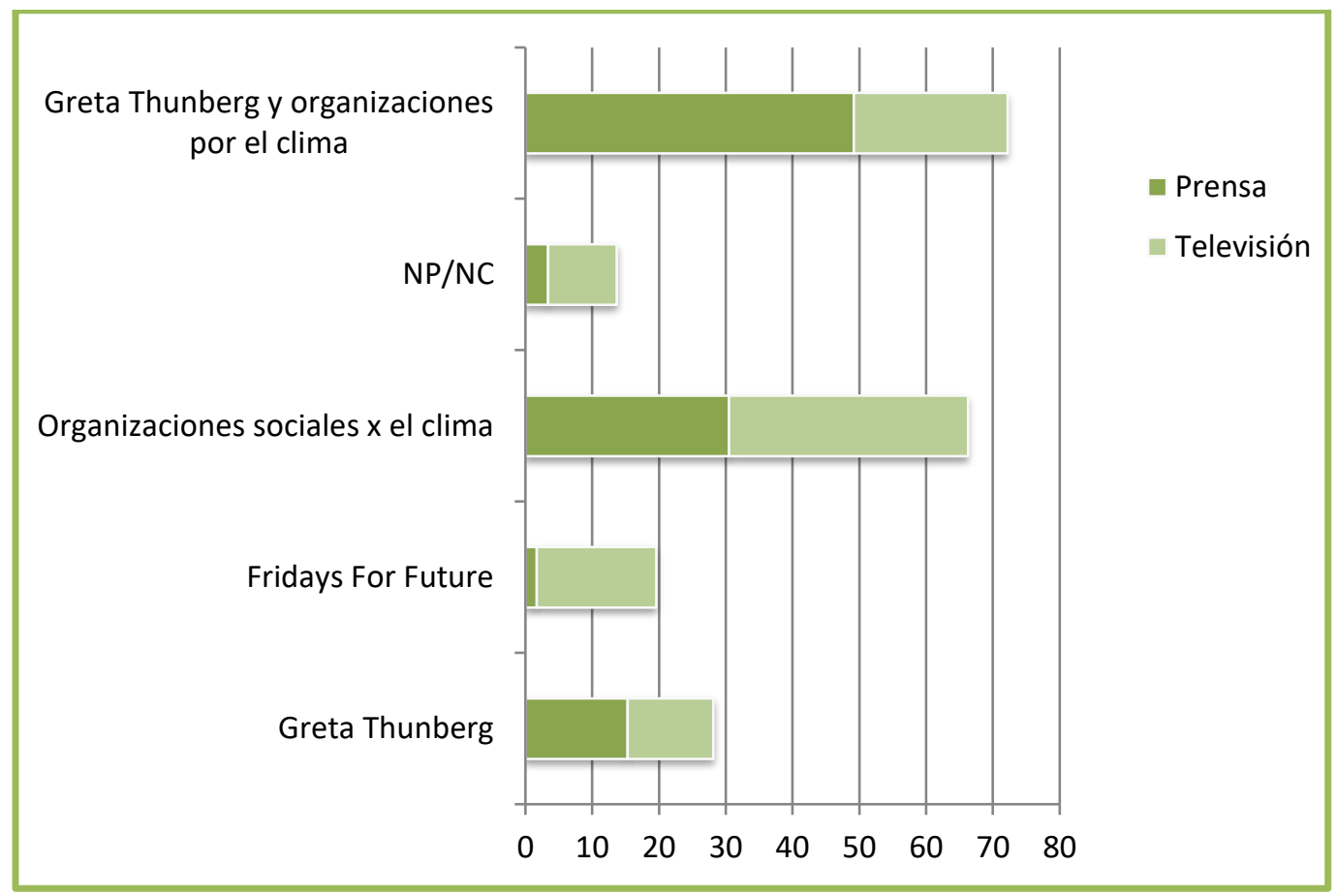

Fuente: elaboración propia

Otros nombres de activistas que aparecen como protagonistas son, en prensa: Alexandria Villaseñor y Xiye Bastida, Bardem, Koro López de Uralde, Licypriya Kangujam y Vanessa Nakate, Sadie McDonald, Lounes Emerard, María Carranza y Fernanda Cruz. En el caso de la televisión, en las fechas analizadas aparecen los nombres de otras organizaciones como Global Citizen, Amigos de la Tierra y Ecologistas en Acción, a los que se añaden nombres propios como Miguel Díaz (Amigos de la Tierra), Macaco, Jorge Drexler, Javier Bardem y Penélope Cruz.

\section{EL MENSAJE Y LA ACTITUD DE GRETA EN LA TELEVISIÓN Y EN LA PRENSA}

A la hora de estudiar las actitudes tanto de Greta como de otros jóvenes se consideran cuatro categorías: positiva (creativo, empático, cualidades), negativa (dudas, recelo, crítico), mixto (ambos anteriores) y neutro (aséptico). Es oportuno 
explicitar que no se valora el acierto o no de las actitudes. De esta manera, una actitud que aparece como negativa puede ser un acierto, y una actitud positiva puede no serlo.

En un 64 \% de las piezas, tanto en la prensa o en televisión, no se dispone de información al respecto. En el resto, prevalece una actitud neutra en prensa y negativa en televisión, seguido en segundo lugar por la actitud positiva en ambos soportes.

Gráficos 8. La actitud de Greta en los medios. Porcentaje de casos.

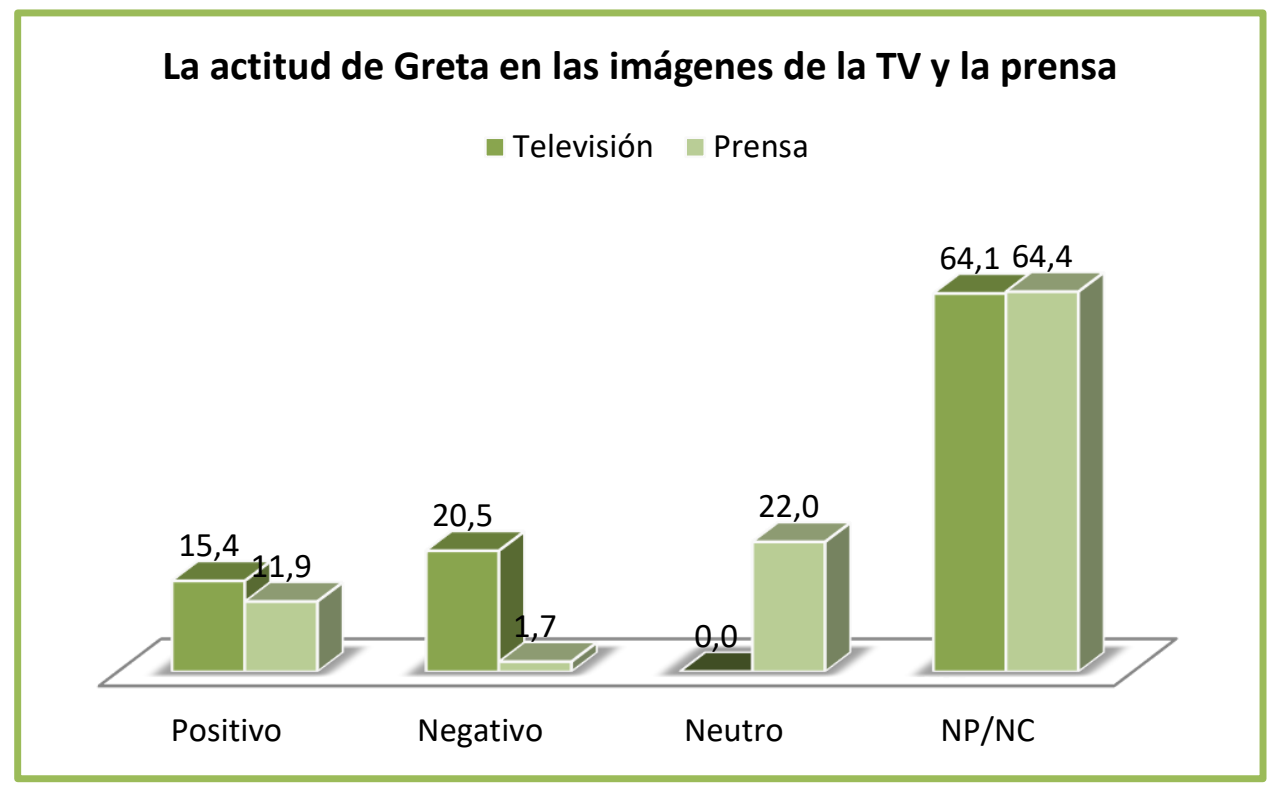

Fuente: elaboración propia 
Serie 1 de imágenes agrupadas. La adolescente Greta Thunberg en la televisión y en la prensa en el año 2019.

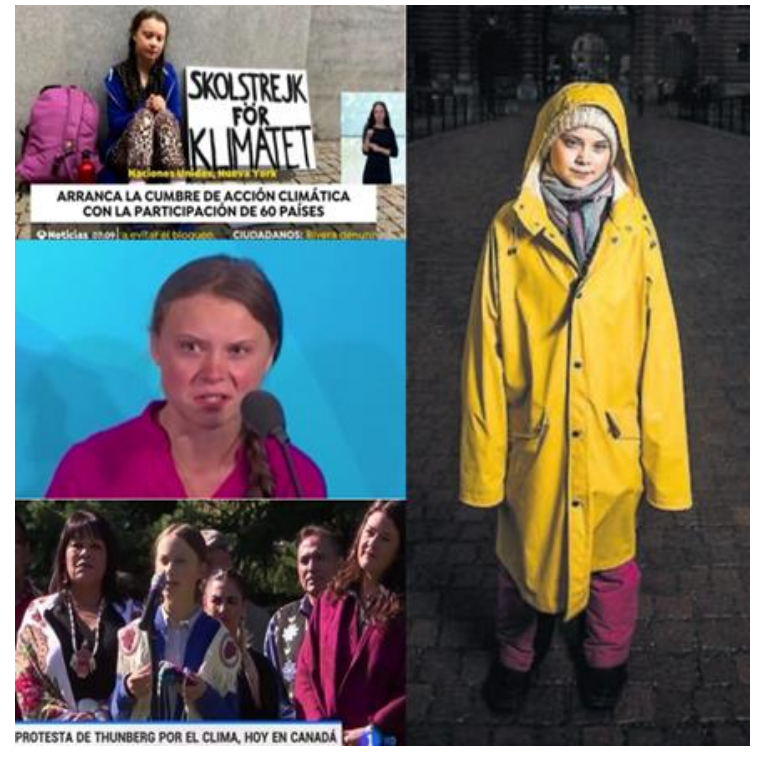

Fuentes (de izquierda a derecha y de arriba a abajo): Antena 3, diario El País (Greta con el chubasquero amarillo), La Sexta y TVE-1.

En la serie 1 de fotografías agrupadas, nos encontramos en primer lugar con la imagen de Greta, un viernes cualquiera, sentada, a modo de protesta, en el suelo de de una calle de Estocolmo. Se trata de una imagen de archivo empleada por los informativos de la mañana de Antena 3 el día 23 de septiembre, antes de que comenzara la cumbre de la Acción climática en Nueva York que se celebraba ese día. Justo debajo de la anterior, tenemos la imagen de Greta grabada ese mismo día mientras declaraba en la sede de Naciones Unidas, dónde pronunció ante los mandatarios las famosas frases: “¿Cómo os atrevéis?" y "Nos habéis robado el futuro". Debajo de esta imagen, encontramos otra de Greta en Montreal cuatro días después, el viernes día 27 de septiembre, día de la huelga mundial por el clima. En la rueda de prensa al final de la manifestación, señaló ante los medios: "Hoy ha sido un gran día" y "Nos hemos hecho demasiado ruidosos para que nos puedan manejar."

Los eslóganes de Greta y de los/as jóvenes movilizados por el clima señalan directamente al cambio climático como el problema más importante para su generación $28:$ "Si nuestro planeta fuera un banco ya lo habríais rescatado", "Si el 
cambio climático nos deja sin futuro, de nada sirve ir a clase", "Ustedes no son lo suficientemente maduros para contar las cosas como son", "No queméis nuestro futuro", "¿Por qué tendría que recoger mi habitación si vosotros tenéis el planeta hecho un desastre?", "Ustedes dicen que aman a sus hijos por encima de todo, pero les están robando su futuro ante sus propios ojos". Por último, uno de los eslóganes de Greta fue "Necesitamos esperanza, pero lo único que necesitamos más que la esperanza es la acción. En lugar de buscar esperanza debemos buscar acción. Y solo entonces vendrá la esperanza".

A la hora de recoger las declaraciones de Greta nos encontramos con diferencias entre la televisión y la prensa debido a que estudian fechas diferentes. Coinciden en que la mayoría de las piezas no contienen declaraciones. Cuando las contienen, en TV prevalece el mensaje de "No hay futuro/nos habéis robado el futuro", seguido de "Actúen, concreten medidas". En prensa, sin embargo, el mensaje con más frecuencia es "No deberían escucharme a mí antes que a otros/as", seguido de "No hay futuro/nos habéis robado el futuro" y de "Escuchen a la ciencia".

\section{LA ACTITUD DE LOS MEDIOS HACIA GRETA Y LOS/AS JÓVENES}

Como hemos podido comprobar en el gráfico 8, la actitud negativa de Greta aparece representada fundamentalmente en el medio televisivo, en un 20\% de los casos. Es también la televisión la que muestra una actitud negativa hacia Greta o hacia los jóvenes manifestantes, si bien esto se produce en tan solo en un 5,1\% de los casos. Esta actitud es prácticamente inexistente en la prensa. Como podemos apreciar en el gráfico 10, tanto para la prensa como para la televisión en España, la actitud del medio hacia los jóvenes activistas y hacia Greta es una actitud fundamentalmente neutra, limitándose a informar sobre su actuación o declaraciones, pero sin entrar en valoraciones sobre su carácter o sobre su comportamiento. Cuando estas valoraciones se hacen, bien sea mediante calificativos o mediante el tono empleado en los 
comentarios, la actitud es mayormente positiva, tanto en la prensa como, en la televisión, dónde la disposición positiva alcanza el 30\% de los casos.

Gráfico 9. La actitud de los medios hacia los jóvenes activistas y hacia Greta. Porcentaje de casos.

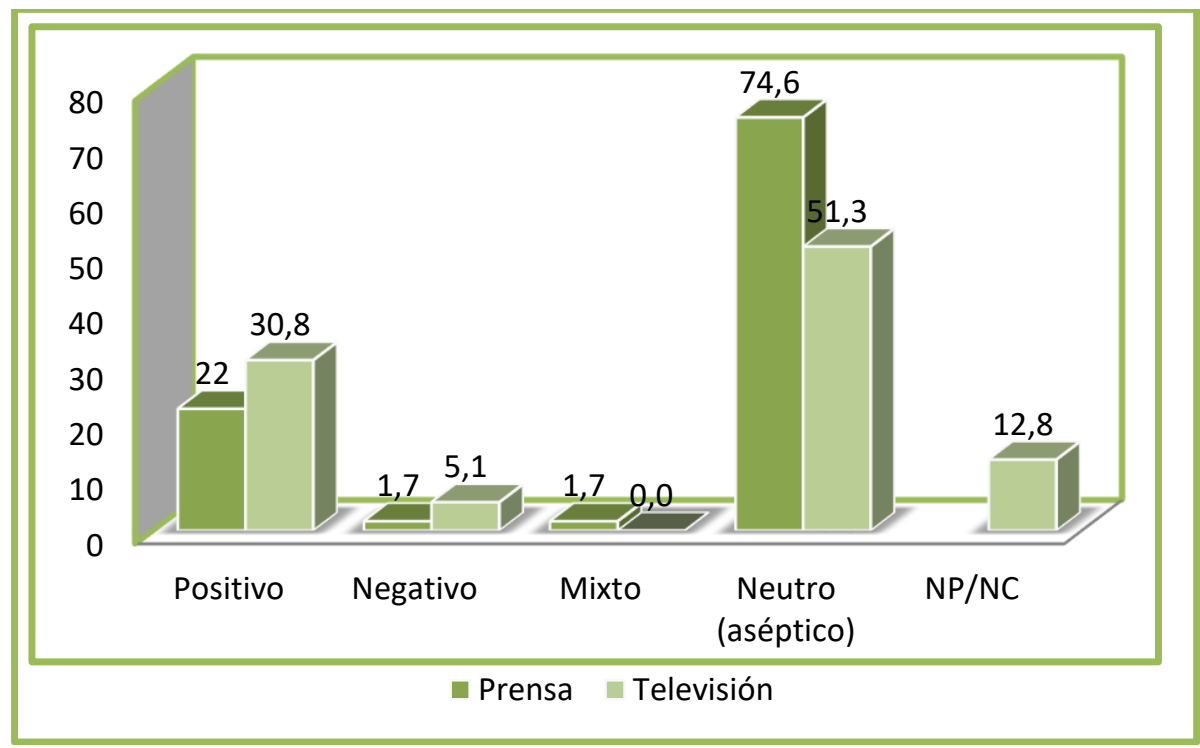

Fuente: elaboración propia

\section{EL TRATAMIENTO DE LA INFORMACIÓN VISUAL EN LA PRENSA Y EN LA TELEVISIÓN}

A continuación se analiza un aspecto concreto del tratamiento informativo de las movilizaciones sociales que guarda relación con la forma en la que se muestran los datos o hechos sobre los que los medios informan. Además del texto en la prensa y las voces de los periodistas en la televisión, estos medios emplean distintos recursos visuales que son analizados para identificar sus características y aplicaciones a la narrativa del acontecer noticioso ligado a las movilizaciones sociales. Se analiza la tipología de los recursos visuales empleados, el número de planos en televisión (imagen en movimiento) y de imágenes en la prensa (imagen fija) por unidad de análisis, tamaño del encuadre y la angulación (eje vertical).

Como se ha indicado anteriormente, las imágenes televisivas tienen una naturaleza secuencial y la captación se produce mediante cámaras de video. Las 
imágenes de los presentadores del programa informativo se producen en directo, es decir, a la vez que se emiten. Sin embargo, la mayor parte de las noticias a las que dan paso los presentadores han sido previamente grabadas y editadas. En cualquier caso, son imágenes que denominamos videográficas y, lógicamente, el 100\% este tipo de imágenes está presente en el 100\% de los registros analizados. Ahora bien, la tecnología permite que las imágenes que vemos puedan estar formadas por varias capas de video que permiten superponer imágenes. En televisión, encontramos que el grafismo aplicado a los rótulos que se superponen a las imágenes añade información que permite contextualizar y comprender el significado de las mismas. Es un recurso que encontramos en casi el 48,5\% de los registros televisivos analizados. En un 5,1\% de los casos encontramos dibujos o ilustraciones y en un 2,6\% el empleo de infografías.

Gráfico 10. Recursos visuales empleados en prensa y televisión para informar sobre las movilizaciones juveniles por el clima.

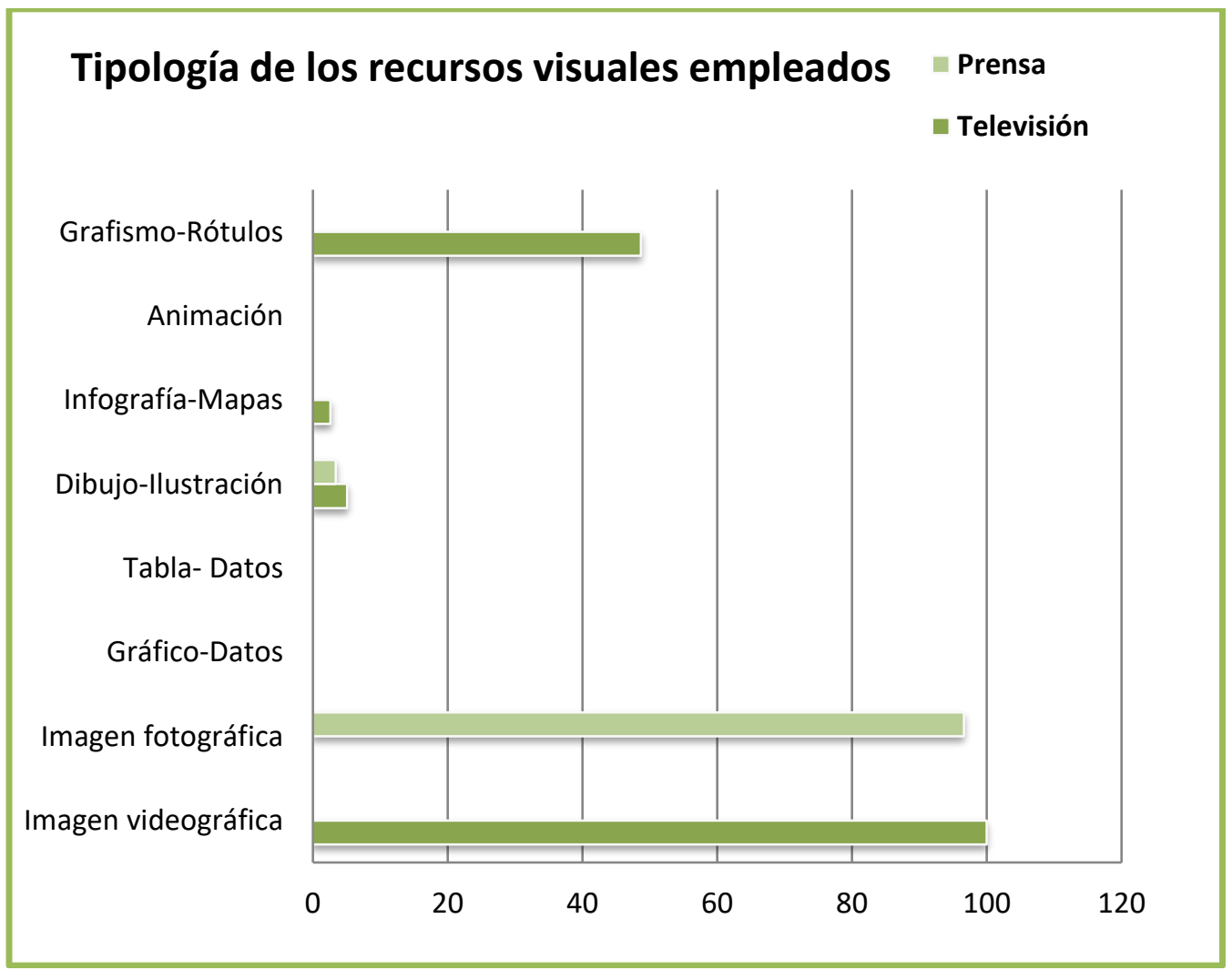

Fuente: elaboración propia. 
Respecto a los recursos empleados por la prensa, encontramos que la inmensa mayoría de las información sobre las movilizaciones por el clima en los diarios analizados, el 96,6\% de los casos, emplea la imagen fotográfica como un elemento esencial de la información. Ahora bien, el empleo de otros recursos visuales es escaso en los registros analizados. Tan sólo un 3,4\% de los casos sustituyen la imagen fotográfica por u dibujo o ilustración.

Respecto al número de imágenes encontradas en cada unidad de análisis de la prensa encontramos que la mayor parte de los casos (30), tan sólo emplea una única imagen. En 12 casos emplea dos imágenes, en 9 casos 3 imágenes y en 8 casos se emplean 4 imágenes.

En el caso de la televisión, la duración media de las informaciones ofrecidas sobre las movilizaciones por el clima es de 99,31 segundos, es decir, muy poco menos de un minuto y cuarenta segundos. Sin embargo, la mediana se sitúa en los 90 segundos, es decir, que la mayor parte de los registros tienen una duración de minuto y medio. La imagen televisiva es imagen secuencial y por tanto cada registro televisivo está compuesto por una sucesión de planos diferenciados en la secuencia temporal cuya duración acabamos de describir. El número de planos en los que aparecen jóvenes activistas en de cada una de las unidades de análisis de la televisión oscila entre 1 y 39 , situándose la media en 12,33 planos y la mediana en 9 planos. 
Tabla 2. Numero de imágenes en prensa y de planos en televisión en los que aparecen jóvenes activistas por unidad de análisis.

\begin{tabular}{|c|c|c|c|}
\hline \multicolumn{4}{|c|}{ Número de imágenes de jóvenes activistas/unidad análisis } \\
\hline $\mathrm{N}^{\circ}$ de planos TV & Porcentaje & $\begin{array}{c}N^{\circ} \text { imágenes } \\
\text { prensa }\end{array}$ & Porcentaje \\
\hline 1 & 11,11 & 1 & 50,84 \\
\hline 2 & 3,7 & 2 & 20,33 \\
\hline 3 & 7,04 & 3 & 15,25 \\
\hline 4 & 7,04 & 4 & 13,55 \\
\hline 5 & 3,7 & & \\
\hline 6 & 11,11 & & \\
\hline 7 & 3,7 & & \\
\hline 8 & 3,7 & & \\
\hline 9 & 3,7 & & \\
\hline 10 & 3,7 & & \\
\hline 11 & 3,7 & & \\
\hline 16 & 7,04 & & \\
\hline 17 & 3,7 & & \\
\hline 19 & 3,7 & & \\
\hline 20 & 3,7 & & \\
\hline 27 & 3,7 & & \\
\hline 29 & 3,7 & & \\
\hline 30 & 3,7 & & \\
\hline 33 & 3,7 & & \\
\hline 39 & 3,7 & & \\
\hline Total & $98,8 \%$ & Total & $99,97 \%$ \\
\hline Media TV & 12,33 planos & Media prensa & 1,91 imágenes \\
\hline Mediana TV & 9 planos & Mediana prensa & 1 imagen \\
\hline
\end{tabular}

Fuente: elaboración propia.

Las imágenes de televisión que representan a los jóvenes activistas han sido clasificadas de acuerdo con las siguientes categorías en función de su contenido:

- Jóvenes manifestándose

- Niños en las manifestaciones (con sus padres)

- Performance

- Jóvenes declarando ante las cámaras

- Greta

- Jóvenes como oradores en los mítines

- Detalles de las pancartas 
En los ejemplos ofrecidos de la televisión, vemos gran diversidad de encuadres, desde el plano general de la cabecera de la manifestación hasta el primerísimo primer plano del joven maquillado cuya cara maquillada simula ser el planeta azul, pasando por los primeros planos o planos medios y enteros de los jóvenes entrevistados. Dada la complejidad del análisis del encuadre en la imagen secuencial, en el análisis de televisión no ha sido cuantificado el número de encuadres posibles para cada plano. En el caso de la imagen en movimiento, el movimiento de la cámara o el cambio de la distancia focal que pueden producirse en el mismo plano, ofrece un gran número de distintos encuadres en el mismo plano que complica el análisis de esta variable. Si a este hecho añadimos que cada pieza de minuto y medio de televisión tiene de media 12 planos, el estudio exhaustivo de esta variable excede con mucho los límites de este estudio. Por este motivo, sólo se ha analizado una imagen (frame de video) que corresponde a uno único plano del registro televisivo analizado. Se ha aplicado un criterio cualitativo para su selección que no ha sido otro que tratar de reflejar la diversidad presente en el contenido de las imágenes protagonizadas por los jóvenes activistas en los distintos canales de televisión. A continuación se muestran las ocho imágenes que se han seleccionado para ilustrar las distintas categorías descritas anteriormente y la creatividad de los jóvenes manifestantes. 
Serie 2 de imágenes agrupadas. Imágenes de jóvenes activistas por el clima emitidas por la televisión en España durante la Semana de Acción Climática del año 2019.

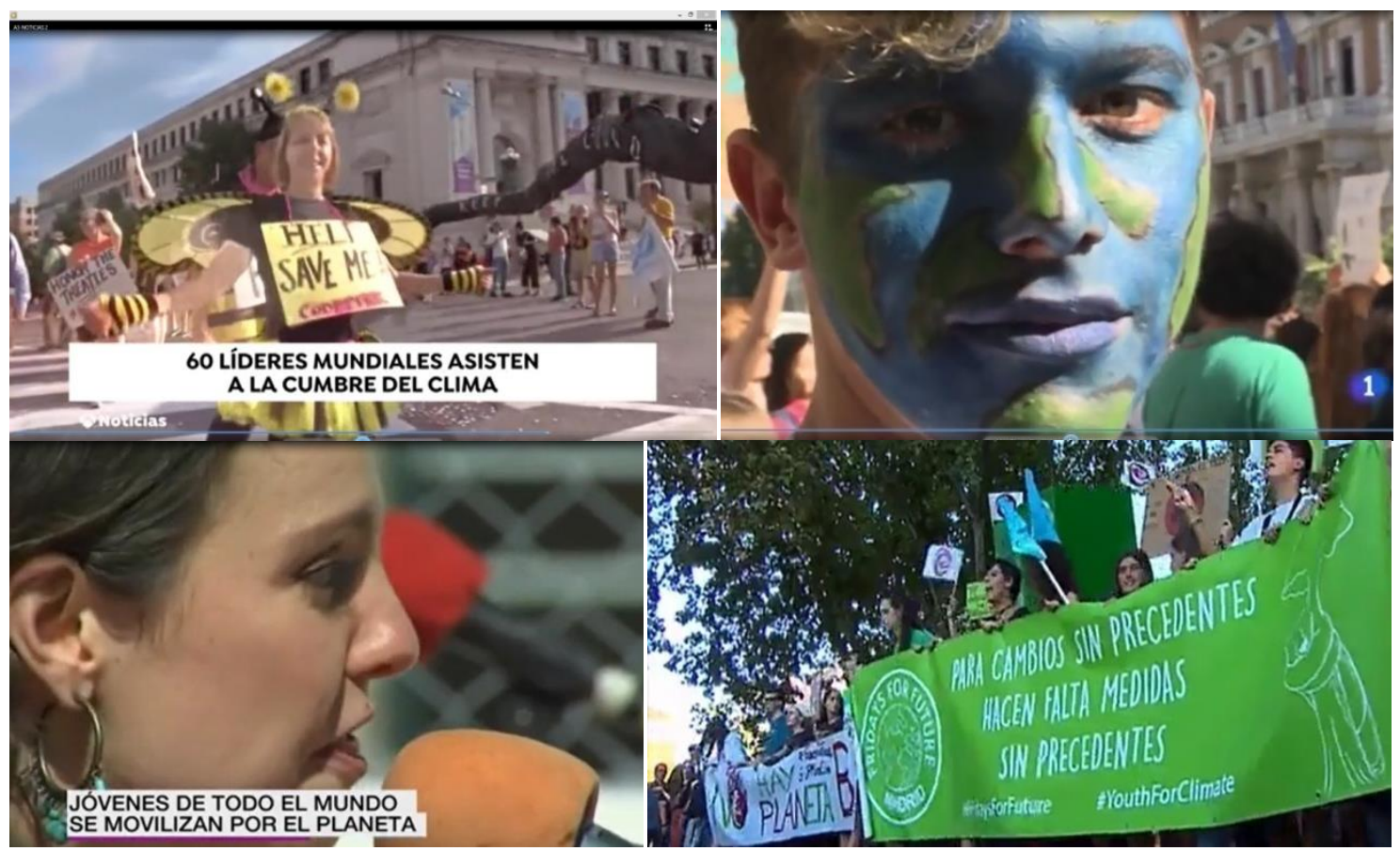

Fuentes (de izquierda a derecha y de arriba a abajo): Antena 3, TVE-1 La Sexta y TVE-1.

En la serie de imágenes agrupadas apreciamos a una joven activista en las calles de Nueva York el día de celebración de la cumbre por la acción climática, llamando la atención sobre el riesgo sin precedentes para especies como las abejas. A continuación, un joven anónimo aparece con el rostro maquillado simulando el planeta azul. Debajo, la joven adolescente de 14 años que lidera el movimiento estudiantil en Nueva Zelanda habla en un mitin el día de la huelga mundial por el clima celebrada el viernes 27 de septiembre. Por último, se muestran dos pancartas que recorrieron Madrid el mismo día de la manifestación en las que se alude al clásico lema "No hay planeta B" o se demandan medidas para un gran cambio social: "para cambios sin precedentes (el cambio climático) hacen falta medidas sin precedentes".

Numerosas imágenes, como la que podemos apreciar en la serie número 4 , muestran a menores en las manifestaciones portando pancartas, muchos de ellos a hombros de su padres. En otras, los activistas llevan a sus hijos a eventos o performances como el "funeral por la muerte de un glaciar" que tuvo lugar el lunes 23 de septiembre con el fin de llamar la atención sobre el riesgo de desaparición de glaciares en tan sólo unas décadas, es decir, en el medio plazo. Muchos jóvenes 
recurren a los disfraces para expresar su mensaje en las movilizaciones por el clima. En la serie inferior de imágenes vemos a un joven vestido con un traje anticontaminación, que puede remitir tanto a los riesgos de contagio por la contaminación de residuos tóxicos como a los posibles riesgos de contagio por enfermedades infecciosas. Por último, el viernes día 27 durante la cobertura de la huelga mundial por el clima, numerosas performances fueron protagonizadas por jóvenes activistas en calles de ciudades de todo el mundo, para llamar la atención sobre un planeta herido que se desangra, como es el caso de la imagen de los jóvenes que se muestra a continuación.

Serie 3 de imágenes agrupadas. Imágenes de jóvenes activistas emitidas por televisión en España durante la Semana de Acción Climática del año 2019.

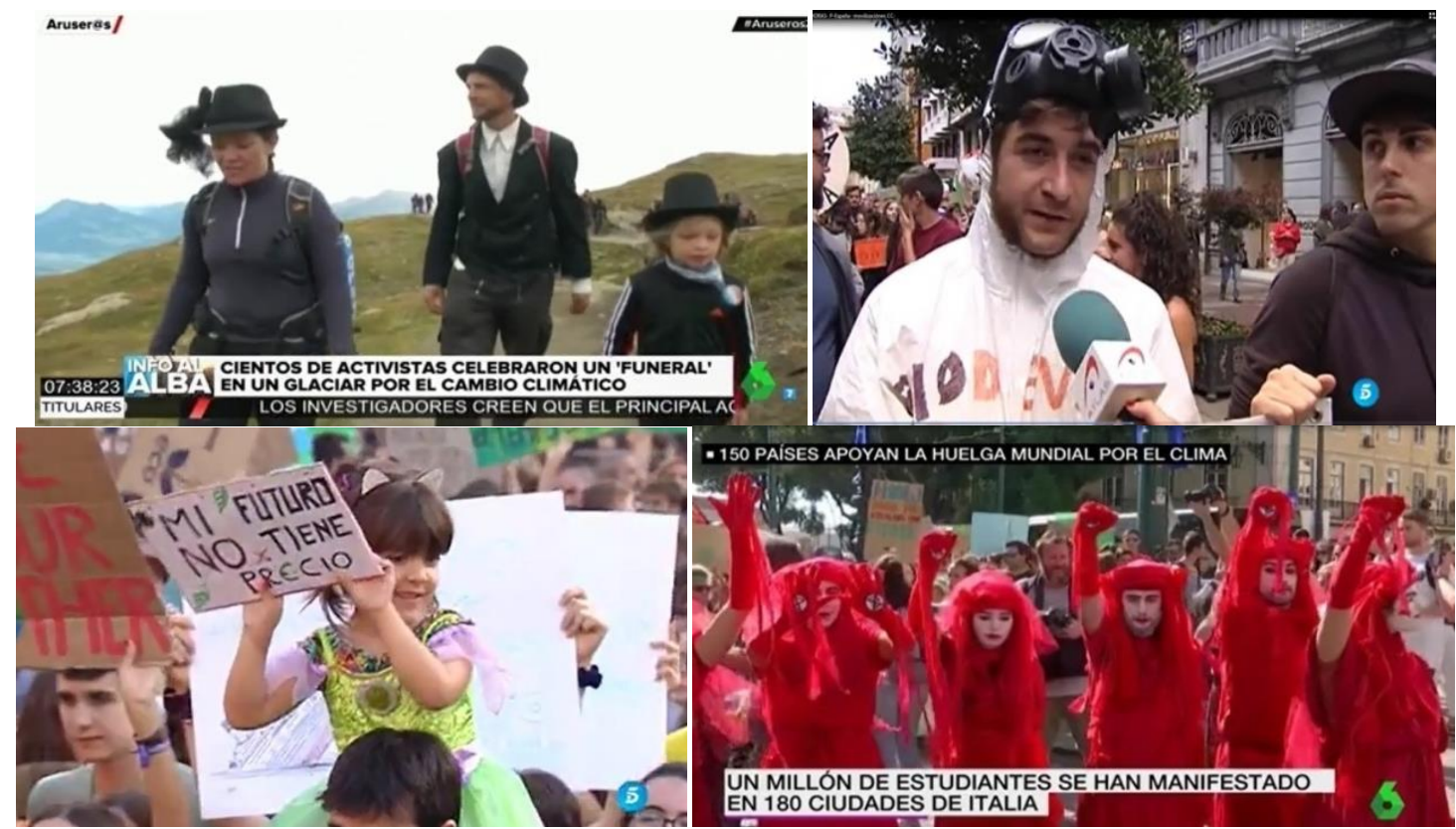

Fuentes (de izquierda a derecha y de arriba a abajo): La Sexta, Tele 5, Tele 5 y La Sexta

A continuación nos centramos en los resultados del análisis del tamaño del encuadre en la prensa. Para el análisis de las imágenes en la prensa, sí se ha llevado a cabo un análisis cuantitativo respecto a los distintos tipos de encuadre encontrados en cada unidad analizada. La mayor parte de las piezas de prensa tiene sólo una imagen y se trata de una imagen fija, lo que facilita el análisis de esta variable, cuyos resultados se muestran en el gráfico 11. 
Gráfico 11. El tamaño del encuadre en las imágenes de la prensa sobre las movilizaciones por el clima.

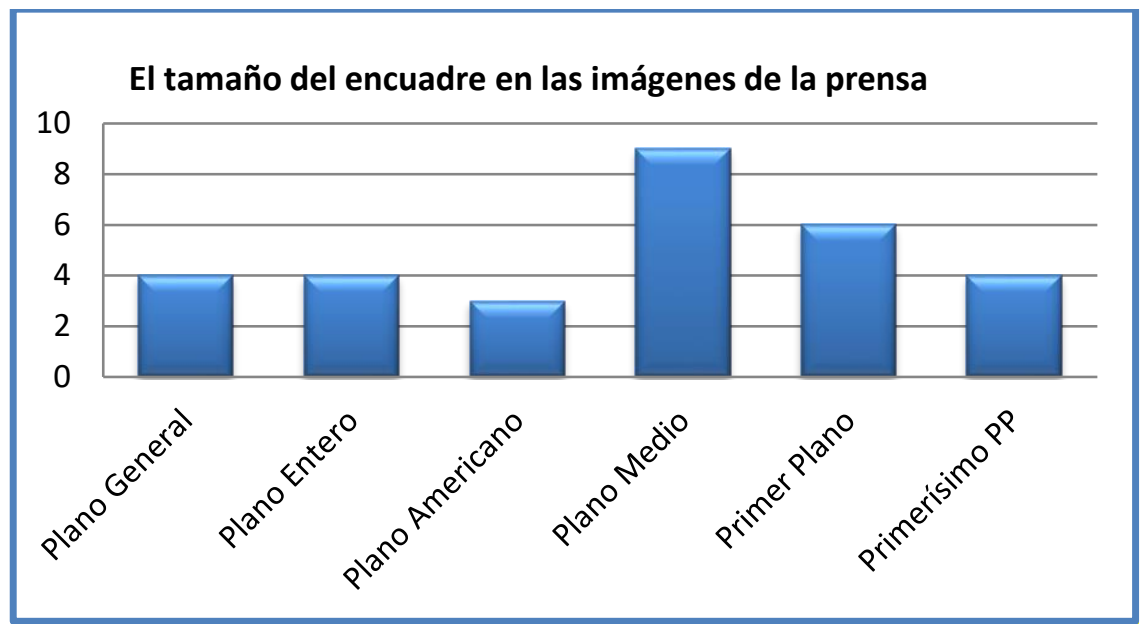

Fuente: elaboración propia.

Como pudimos apreciar en la tabla 2, las publicaciones en prensa que sólo contienen una imagen son más el 50\% del total. Estas publicaciones emplean mayoritariamente un tamaño de encuadre que permite apreciar con detalle la identidad y la expresión de la persona que es fotografiada (el 96\% de las imágenes son fotografías). Se trata de encuadres cuyo tamaño definimos en función de la extensión de la figura humana que nos muestran. Predominan los planos medios y primeros planos, aunque también encontramos la misma frecuencia en primerísimos primeros planos y planos enteros. De esta manera, la fotografía empleada permite personalizar la información ofreciendo la imagen de uno de los protagonistas.

El plano general es menos frecuente cuando la publicación cuenta con tan solo una imagen. Los planos generales empleados para la cobertura informativa de las movilizaciones por el clima, tanto en la prensa como en la televisión, nos ofrecen una perspectiva amplia de las manifestaciones o de acciones realizadas en espacios abiertos como mítines o performance. 
Serie 4. Imágenes agrupadas de publicaciones de la prensa en España sobre las movilizaciones climáticas en 2019.
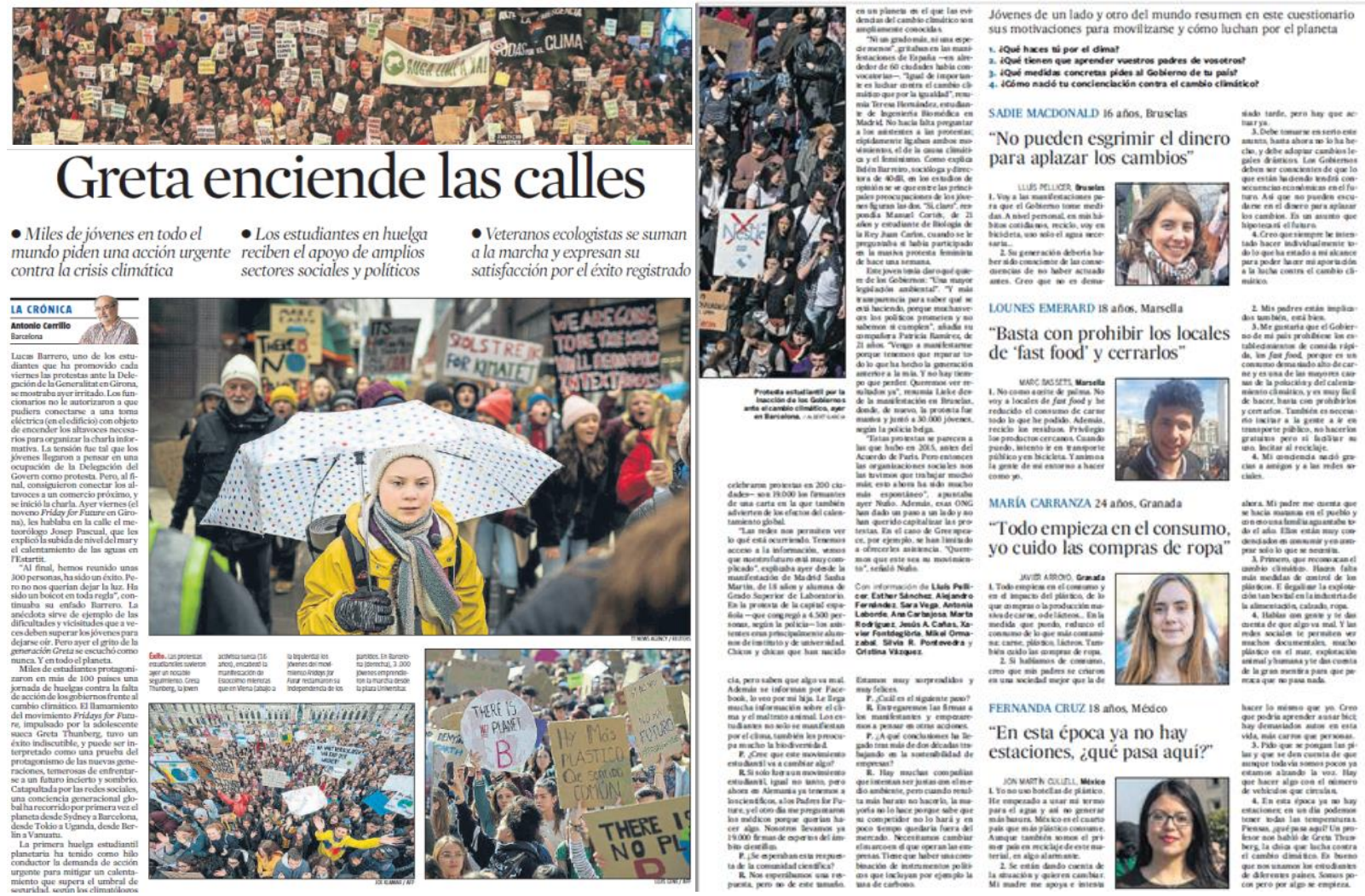

Fuentes (de izquierda a derecha y de arriba a abajo): Imagen de las movilizaciones por el clima de la portada de El País (07/12/2019), las cinco imágenes del reportaje de Manuel Planelles en El País y la crónica de Antonio Cerrillo en La Vanguardia, que incorpora 3 imágenes de Greta en plano medio y dos planos generales de las manifestaciones.

Para concluir con esta exposición, se muestran en el gráfico 12 los resultados del análisis de la contingencia entre dos variables: la actitud del medio hacia los jóvenes activistas y la angulación vertical de la cámara.

Desde que se descubriera la identificación primaria que experimenta el espectador con el punto de vista de la cámara ${ }^{29}$, el lenguaje audiovisual nos ofrece muchos ejemplos sobre cómo el ángulo de la cámara respecto al eje vertical ha sido empleado por muchos/as realizadores/as a lo largo de la historia del cine como un recurso expresivo que permite al espectador observar la escena o al protagonista desde arriba (plano picado), desde abajo (plano contrapicado) o a su altura (angulación neutra). Por citar un referente popularmente conocido, el director Orson Welles

\footnotetext{
${ }^{29}$ J. Aumont, A. Bergala, M. Marie \& M. Vernet, Estética del cine (Titivilus, 198, $2^{\text {a }}$ Edición, 1996)
} 
empleó en muchas de sus obras ${ }^{30}$ este recurso para mostrar más poderosos a sus personajes mediante un ángulo contrapicado, o aminorar su peso dramático mediante un ángulo picado. Nos preguntábamos si estas claves propias del lenguaje audiovisual que todos profesionales de la fotografía han estudiado e interiorizado estaban presentes en las imágenes registradas por los profesionales para la comunicación social de las movilizaciones por el clima. En segundo lugar, nos preguntábamos si la angulación de la cámara (neutra, picado o contrapicado) estaba asociada mostraba alguna correlación con la variable que nos ha permitido analizar la actitud del medio hacia los jóvenes activistas.

Gráfico 12. La actitud del medio hacia los jóvenes activistas en relación con el ángulo de la cámara (eje vertical) en las imágenes de la prensa.

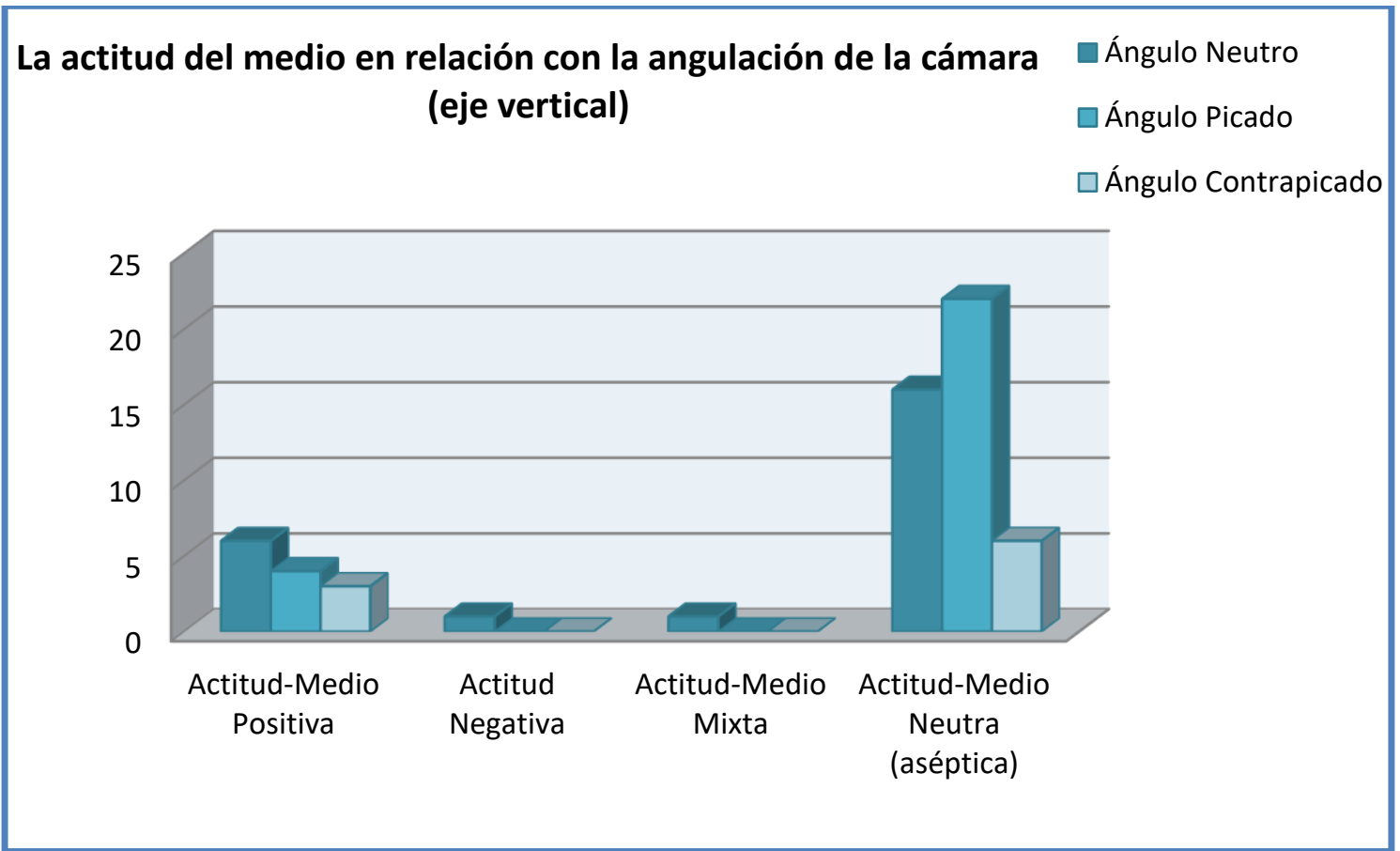

Fuente: elaboración propia.

Como podemos apreciar en el gráfico 12, la angulación picada y neutra son las más frecuentes. La actitud predominante del medio hacia los jóvenes es neutral o aséptica. Y cuando esto sucede, la mayor parte de las imágenes tienen una ángulo vertical picado o neutro, lo que significa que la angulación de la cámara no obedece a una intencionalidad dramática sino que guarda relación con otros muchos factores 
que condicionan el trabajo del reportero/a gráfico, como son la necesidad de ganar altura en las manifestaciones para poder captar la imagen, o el hecho de que Greta y muchos de los manifestantes son niños y niñas de menor estatura que los fotógrafos y, por consiguiente, el ángulo natural para el disparo de las instantáneas es el picado. Por otra parte, observamos como la actitud positiva del medio hacia los jóvenes incluye los tres tipos de angulaciones analizadas.

Serie 5 de imágenes agrupadas. Jóvenes en las manifestaciones por el clima anticipándose al uso de la mascarilla para denunciar, tanto la pérdida de la salud con la crisis climática como la crisis biológica causada por la pérdida de la biodiversidad.



Fuentes: TVE-1, Antena 3 y La Sexta 


\section{CONCLUSIONES}

Los resultados indican que las movilizaciones climáticas han sido atendidas en primer lugar por medios de comunicación identificados como progresistas: La Sexta en televisión y El País en la prensa analizada. En segundo lugar se encuentra el canal de la televisión pública nacional TVE-1 (grupo RTVE). Este resultado coincide con los obtenidos en investigaciones anteriores ${ }^{31}$ sobre la cobertura del cambio climático, que apuntaban a las televisiones públicas (nacionales y autonómicas) como las que más frecuentemente comunicaban el cambio climático y que situaban a La Sexta como el canal privado que ofrecía mayor cobertura informativa sobre este fenómeno.

Las piezas analizadas en la Semana de Acción Climática de 2019 muestra la fuerte influencia de las distintas agendas de las esferas públicas en la cobertura mediática. Si bien el día 23 de septiembre los medios reprodujeron una dialéctica argumental y visual entre los marcos social y político, el día 25 prevaleció el marco científico con la presentación del Informe del IPCC y el día 27, día de la huelga mundial, lo hizo el marco social. Es precisamente el enmarcado social el más novedoso en la cobertura mediática del cambio climático de 2019 merced a las multitudinarias movilizaciones por el clima y el papel adquirido por los activistas las en Cumbres de política internacional. Otro marco de referencia que ha cambiado es la solución, que ha sido el tema que ha predominado tanto en la prensa como en la televisión.

Los géneros periodísticos predominantes para la cobertura informativa de las movilizaciones sociales de los jóvenes por el clima en la prensa española son la noticia y el reportaje a partes iguales, seguido de la crónica. En la televisión se encuentra presente en los informativos diarios de manera destacada (un 72\%). Tímidamente, el cambio climático ha logrado salir del reducto de los noticiarios para adentrarse en los programas de debate sobre la actualidad y en las tertulias de los programas magacines.

31 G. Teso, Comunicación y representaciones del cambio climático: El discurso televisivo y el imaginario de los jóvenes españoles (Tesis Doctoral, Madrid: Facultad de Ciencias de la Información de la Universidad Complutense de Madrid, 2016). Disponible en https://eprints.ucm.es/41736/ 
En el caso de la televisión, la duración media de las informaciones ofrecidas sobre las movilizaciones por el clima es de un minuto y cuarenta segundos, si bien la mayor parte de los registros tienen una duración de minuto y medio. El promedio de número de planos en los que aparecen jóvenes activistas en cada una de las unidades de análisis de la televisión es de 12,33 planos. En prensa, la mayor parte de las piezas tiene sólo una imagen y la fotografía como principal categoría de imágenes empleadas. Predominan los planos medios y primeros planos, aunque también encontramos la misma frecuencia en primerísimos primeros planos que en los planos enteros. Estos tamaños de encuadre próximos a la figura humana, nos hablan de la personalización de la información en la prensa ofreciendo la imagen de los protagonistas.

El carácter global, tanto del fenómeno del cambio climático como del movimiento Fridays For Future como principal agente dinamizador de las protestas, provoca que el contexto mundial sea el que prevalezca en las piezas analizadas en ambos soportes, con mayor proporción en el caso de la prensa. En la televisión, el ámbito estatal se encuentra en segundo lugar debido a la intensa cobertura de las manifestaciones que tuvieron lugar en toda las ciudades de España el día 27 de septiembre. El futuro inmediato o presente es el contexto temporal predominante.

La cobertura de las movilizaciones por el clima ha convertido a los activistas en los protagonistas de las informaciones relacionadas con el cambio climático, desplazando a los políticos a un segundo término. En la prensa, los activistas son protagonistas en la totalidad de los artículos debido a los términos de búsqueda utilizados para el análisis. En el caso de la televisión, comparten protagonismo en pantalla los jóvenes activistas con los periodistas profesionales destacados como mediadores en el lugar de los hechos. Los políticos ocupan la tercera posición en la televisión. Tanto en la prensa como en la televisión, destaca el protagonismo de Greta Thunberg al frente de las movilizaciones sociales por el clima, especialmente del movimiento Fridays For Future. Greta acapara un protagonismo mayor en la prensa que en la televisión, quizás porque en los diarios se usan menos imágenes y éstas se enfocan hacia la joven sueca como el rostro de las movilizaciones. 
A la hora de recoger las declaraciones de Greta nos encontramos con diferencias entre la televisión y la prensa debido a que estudian fechas diferentes. En prensa, el mensaje con más frecuencia es "No deberían escucharme a mí antes que a otros/as", seguido de "No hay futuro/nos habéis robado el futuro" y de "Escuchen a la ciencia". En televisión prevalece el mensaje de "No hay futuro/nos habéis robado el futuro", seguido de "Actúen, concreten medidas". En la prensa prevalece una actitud neutral de Greta y en televisión prevalece una actitud negativa, fundamentalmente por el repetido eco de las palabras que dirigió a los mandatarios en la cumbre de Acción Climática: "How dare you"! Por otra parte, la actitud de los medios hacia Greta es fundamentalmente neutra, limitándose a informar sobre su actuación o declaraciones, pero sin entrar en valoraciones sobre su carácter o sobre su comportamiento. Cuando estas valoraciones se hacen, bien sea mediante calificativos o mediante el tono empleado en los comentarios de la televisión, la actitud es mayormente positiva, tanto en la prensa como, en la televisión.

Los recursos visuales empleados en prensa y televisión para informar sobre las movilizaciones juveniles por el clima son, de manera destacada, la imagen videográfica en el caso de la televisión y la fotografía en el caso de la prensa. En televisión se emplea con frecuencia el uso de recursos gráficos añadir información o para contextualizar las imágenes, si bien destaca en ambos soportes la escasa utilización de otro tipo de recursos visuales analizados.

Entre los efectos de las movilizaciones juveniles, apoyadas por ciudadanía adulta, se pueden encontrar: un volumen inaudito movilización ciudadana por el clima a nivel mundial, europeo y nacional; la identificación de la causa ambiental por parte de toda una generación; y haber logrado uno de sus objetivos: que se declarara institucionalmente la emergencia climática32. En España, el Congreso de los Diputados aprobó la Declaración de Emergencia Climática el 17 de septiembre de 2019 por 311 votos a favor y 24 votos en contra. Dos meses después, el 28 de noviembre de 2019, el Parlamento Europeo declaró el estado de emergencia climática con 429 votos a favor, 225 en contra y 19 abstenciones. Posteriormente, el 21 de enero de 2020, el 
Consejo de Ministros español aprobó la Declaración ante la Emergencia Climática y Ambiental. En apenas unos meses, la emergencia climática se ha introducido en la política europea y nacional, así como en otros ámbitos menores. Y no como un elemento más, sino como uno de los dos ejes principales de la política europea, junto a las tecnologías, y como una de las vicepresidencias del gobierno español actual. Posiblemente no hubiera sucedido sin las movilizaciones ciudadanas ligadas a los avisos de la comunidad científica. A día de hoy, más de 800 de millones los ciudadanos/as viven en regiones con declaración de emergencia climática33.

Como hemos visto en las imágenes de este estudio, los jóvenes, además de a sus pares, han movilizado a ciudadanos de otras franjas de edad, que han salido a las calles a reclamar lo que los jóvenes consideran un derecho humano vital: el derecho a vivir en un medio ambiente sano. De forma premonitoria, hemos visto a muchos jóvenes acudir a las manifestaciones por el clima con mascarillas y trajes anticontaminación, conceptualizando el cambio climático como un problema para la salud humana. También reclaman en sus pancartas el derecho a la vida de otras especies compañeras de viaje. La crisis del Covid 19 nos ha enseñado que conservar la biodiversidad es clave para mantener ecosistemas saludables para todas las especies, también para la nuestra. Confiamos en que la "nueva normalidad" que la humanidad tendrá que construir tras superar la pandemia mundial ocasionada por el Covid, atienda a estas reivindicaciones que los jóvenes han llevado a los medios de comunicación para su reproducción social.

\section{REFERENCIAS}

A. Nacu-Schmidt, J. Katzung y M. Boykoff, "A Review of Media Coverage of Climate Change and Global Warming in 2019", Media and Climate Change Observatory, Colorado University (2020), en https://scholar.colorado.edu/concern/articles/qn59q4937 
Back, Cameron \& Tanner, "Children and Disaster Risk Reduction: Taking stock and moving forward" (UNICEF, 2009).

BBC, "You must unite behind the science. You must take action. You must do the impossible. Because giving up can never ever be an option" Greta Thunberg US Congress, Washington DC (2019).

Boykoff, M. et al., World Newspaper Coverage of Climate Change or Global Warming, 2004-2020. Media and Climate Change Observatory Data Sets. Center for Science and Technology Policy Research, Cooperative Institute for Research in Environmental Sciences, University of Colorado (2000).

Climate Emergency Declaration "Climate emergency declarations in 1,496 jurisdictions and local governments cover 820 million citizens" (20 de mayo de 2020). Disponible en https://climateemergencydeclaration.org/climate-emergencydeclarations-cover-15-million-citizens /

D. Robert, "Social tipping points are the only hope for the climate", en vox.com (29 de enero de 2020). Disponible en https://www.vox.com/energy-andenvironment/2020/1/29/21083250/climate-change-social-tipping-points

E.M. Vavilov, "Lessons about activism from a Swedish high school student: A rhetorical analysis of Greta Thunberg's public speeches on climate change" (Master Thesis, Jönköping University, 2019). Retrieved from http://urn.kb.se/resolve?urn=urn:nbn:se:hj:diva-46317

G. Teso, Comunicación y representaciones del cambio climático: El discurso televisivo y el imaginario de los jóvenes españoles. (Tesis Doctoral, Madrid: Facultad de Ciencias de la Información de la Universidad Complutense de Madrid, 2016). Disponible en https://eprints.ucm.es/41736/

IPCC, Cambio Climático 2014: Impactos, Adaptación y Vulnerabilidad (Contribución del Grupo de trabajo II al Quinto Informe de Evaluación del Grupo Intergubernamental de Expertos sobre el Cambio Climático, 2014).

J. Aumont, A. Bergala, M. Marie \& M. Vernet, Estética del cine (Titivilus, 198, 2ª Edición, 1996).

J. Boehnert, "Maping Climate Communitacion". Blog Ecolabs, (2014). Disponible en: http://ecolabsblog.files.wordpress.com/2014/05/mapping-climatecommunication-boehnert-may2014-v-1-flatlocked.pdf (28-05-2020).

J. Jung, P. Petkanic, D. Nan, J.H. Kim, "When a Girl Awakened the World: A User and Social Message Analysis of Greta Thunberg" Sustainability 12(7), ( 2020), 2707

J. Mitry, Estética y Psicología del Cine I. Las estructuras (Madrid: S. XXI de España Editores S.A., 1984). 
J. Painter (2013), Climate Change in the Media: reporting risk and uncertainty Climate Change in the Media: Reporting Risk and Uncertainty (Oxford: RISJ, 2013).

J. Villafañe, Introducción a la Teoría de la imagen (Madrid: Ediciones Pirámide, 2011).

J.A. Gaitán y J.L. Piñuel, Técnicas de Investigación en Comunicación Social (Madrid: Ed. Síntesis, 1998)

J.M. Zafra, "Jeremy Rifkin: «Estamos ante la amenaza de una extinción y la gente ni siquiera lo sabe" (23 de abril de 2020), Climática. Disponible en https://www.climatica.lamarea.com/jeremy-rifkin-entrevista/

M. Arias Maldonado, Antropoceno. La política en la era humana (Barcelona: Taurus, 2018).

M. McLuhan \& B.R. Powers, The Global Village (Oxford University Press, 1989).

Mariangela La Manna, "Cambiamento climatico e diritti umani delle generazioni presenti e future: Greta Thunberg (e altri) dinanzi al Comitato sui diritti del fanciullo", in Diritti umani e diritto internazionale (1/2020), 217-223

N. Smith and H. Joffe, "How the public engages with global warming: A social representations approach", Public Understanding of Science 22(1) (2012) 16-32.

P.J. Crutzen \& E.F. Stoermer, "The Anthropocene", Global Change Newsletter 41 (2000), 17-18.

R. Entman, "Framing: Toward Clarification of a Fractuired Paradigm". Journal of Communication 41 (1993), 51-58.

R. Fernández-Reyes, "Crónica de la cobertura del cambio climático en prensa de 2019".

https://recambiacambioclimatico.files.wordpress.com/2020/01/16.-resumen2019.pdf

R. Fernández-Reyes, "Greta cataliza la imagen del movimiento internacional" en EFEverde (15 de marzo de 2019). Disponible en https://www.efeverde.com/blog/creadoresdeopinion/greta-imagen-movimientointernacional/

R. Fernández-Reyes, "Los movimientos por el clima, motores de la declaración de emergencia climática" en EFEverde (7 de mayo de 2019). Disponible en https://www.efeverde.com/blog/creadoresdeopinion/clima-movimientos /

R. Fernández-Reyes, J.L. Piñuel-Raigada y J.C. Águila-Coghlan, "Contraste de la cobertura periodística del cambio climático y del calentamiento global en España y en el ámbito internacional: IV-V Informes del IPCC y Bali-Copenhague-París", Revista Latina de Comunicación Social, 72 (2017), 1.165 a 1.185. 
R. Fernández-Reyes, R. and I. Jiménez Gómez, Spanish Newspaper Coverage of Climate Change or Global Warming, 2000-2020 (2020), en https://sciencepolicy.colorado.edu/icecaps/research/media_coverage/spain/inde x.html

R. Lawson, "Resisting eco-misogyni in online spaces: using corpus linguistic to investigate reactions towards Greta Thunberg" (2019). Disponible en http://www.academia.edu/RobertLawson

S. Murray, "Framing a Climate Crisis: A descriptive framing analysis of how Greta Thunberg inspired the masses to take to the streets" (Dissertation, Uppsala University, 2020). Retrieved from http://urn.kb.se/resolve?urn=urn:nbn:se:uu:diva-402643

S.J. O'Neill and S. Nicholson-Cole, "Fear won't do it: Promoting positive engagement with climate change through visual and iconic representations". Sciene Communication 30(3) (2009), 355-379.

Ted MacDonald "How broadcast TV networks covered climate change in 2019" (27 de febrero de 2020). Disponible en https://www.mediamatters.org/broadcastnetworks/how-broadcast-tv-networks-covered-climate-change-2019

Thackeray et al., "Civil disobedience movements such as School Strike for the Climate are raising public awareness of the climate change emergency", Global Change Biology 26(3), (January 2020).

V. Rull del Castillo, El Antropoceno (Madrid: Los libros de Catarata, 2018).

Z. Bergmann \& R. Ossewaarde, "Youth climate activists meet environmental governance: ageist depictions of the FFF movement and Greta Thunberg in German newspaper coverage", Journal of Multicultural Discourses (2020). 


\title{
The images of youth climate mobilizations in the press and television in Spain
}

\begin{abstract}
The 2019 climate mobilizations have been a novelty in climate action. A new generation of adolescents and young people have managed to draw the attention of society to the challenge of climate change, requiring government leaders to take sufficient measures to meet the Paris Agreement on Climate Change, pointing to science as a reference. This historic milestone has had Greta Thunberg as the face of the Fridays For Future student movement along with other organizations. The general objective of this article is to study the representation offered by the media of environmental activism carried out by young people in the face of the climate emergency. The methodology used has been the content analysis on television and in the press based on a structural sampling. Among the effects of youth mobilizations, supported by adult citizenship, we can find: an unprecedented volume of citizen movements for climate at global, European and national scale; the identification of the environmental issue by a whole generation; and to have achieved one of its objectives: the climate emergency declared institutionally.
\end{abstract}

Keywords: climate change, youth mobilizations, Greta Thunberg, communication, images.

Recibido: 30/05/2020

Aprobado: 26/08/2020 